\title{
FUERZA AÉREA COLOMBIANA Y OPERACIONES DECISIVAS 1998-2015
}

\author{
RICARDO ESQUIVEL TRIANA ${ }^{l}$ \\ En cualquier caso, Colombia existe como nación en el mundo actual \\ BusHNELL, 1994. p. 15
}

\section{INTRODUCCIÓN ${ }^{2}$}

En febrero de 2012 Colombia logró que el grupo armado ilegal de mayor tamaño reiniciara diálogos para el cese de sus exacciones ${ }^{3}$. Escasos cuatro meses antes la Fuerza Aérea Colombiana lideró la operación 'Odiseo' en la cual resultó neutralizado el máximo cabecilla de ese grupo denominado FARC ${ }^{4}$. Podría inferirse que con esta operación la Fuerza Aérea fue decisiva para acercar el cese del conflicto armado en Colombia; también podría admitirse que una operación no era suficiente para debilitar al grupo y forzarlo a dialogar. Desde el concepto de victoria decisiva (GRAY, 2012) ambas inferencias se confirman mutuamente.

En primer lugar, incluso en un enfoque de guerra popular prolongada, el objetivo de la guerra es desarmar las fuerzas del contrincante o "privarlas de su capacidad de resistencia, y no significa aniquilarlas a todas físicamente" (MAO, 1968, p. 160).

1 Ph. D. en Historia. Asesor Historia-Fuerza Aérea Colombiana, 2015-2016. Comentarios a: resquivelt@ unal.edu.co

2 Informe de investigación adscrito al proyecto 'Historia FAC 1998-2015', Grupo de investigación 'Análisis en Contexto'-Fuerza Aérea Colombiana (Dirección de Análisis de Contexto y Posconflicto). Los borradores previos se beneficiaron de comentarios de los oficiales FAC: CP. Edison Duarte Parada, CP. Nora Patricia Gutiérrez Rodríguez y ST. Javier Alberto Castrillón Riascos, como de la politóloga (PUJ) Dalia Rodríguez Q. Otra versión modificada se publicó como artículo en EsQuIVEL, R. (2016, Enero-Julio). La Fuerza Aérea Colombiana y el cese del conflicto armado (1998-2015). Rev. Cient. Gen. José María Córdova, 14 (17).

3 Entre febrero 23 y agosto 26 de 2012 se realizó, en La Habana, el "Encuentro exploratorio" con el grupo para definir una agenda de diálogo para la paz. La mesa para dialogar sobre esta agenda se instaló en octubre de ese año, en Oslo (Noruega), y comenzó sus actividades en La Habana (Acuerdo general..., 2012).

4 La transcendencia del dialogo entre el gobierno y ese grupo no necesita debate. Pero siendo aquel un 'grupo armado organizado ilegal', según el DIH, aquí siempre se mencionará así o con sus relativos: 'grupo armado ilegal' o 'grupo ilegal'. Tampoco se asumen los términos del discurso usado por el grupo para describir su devenir porque, según un Manual de Redacción periodística, es un deber de responsabilidad social y de imparcialidad informativa (MENDOZA, 2006. p. 1-29). 
En la operación citada el relevo del cabecilla pudo ser fácil, aunque abrupto, siendo más complejo restablecer la moral de los subalternos que veían amenazados a sus máximos jefes. Solo por esto la operación 'Odiseo' fue una victoria decisiva de la Fuerza Pública porque contribuyó a debilitar la "capacidad de resistencia" del grupo. Si se considera que desde 1998 se han desarrollado operaciones con resultados similares, la noción de victoria adquiere plena confirmación.

En segunda instancia lo decisivo de las operaciones, hasta hoy, es evidente al contrastar el reinicio de diálogos en 2012 con su precedente de 1998. En esta última la Fuerza Pública se recuperaba de dos años de ataques por grandes destacamentos del grupo. En parte por ello, a un mes de posesionarse, el presidente electo Andrés Pastrana (1998-2002) se reunió con el anterior máximo cabecilla y firmaron un acuerdo preliminar para iniciar los diálogos. Sin embargo, enseguida el grupo lanzó una serie de 62 ataques contra instancias gubernamentales, el principal contra la base antinarcóticos de la Policía en Miraflores (Guaviare). Aun así, para iniciar los diálogos, el grupo exigió desalojar la Fuerza Pública de una zona entre Caquetá y Meta y, de nuevo, en noviembre de ese año, el grupo lanzó contra Mitú (Vaupés) el más grande de sus ataques.

El contraste sugiere que, en 1998, el grupo tenía la iniciativa para imponer condiciones. Justo ante el ataque a Mitú la Fuerza Aérea Colombiana lideró una operación decisiva, Vuelo de Ángel, que al recuperar la ciudad frustró los planes de largo plazo de aquel grupo e inauguró su debilitamiento. Todo lo anterior nos lleva a preguntar ¿cómo la Fuerza Aérea se convirtió en el poder decisivo para el cese del conflicto? ¿Cómo se caracterizan las operaciones decisivas que lideró la Fuerza Aérea al efecto?

La respuesta tentativa es que, entre 1998 y 2012 la Fuerza Aérea Colombiana lideró operaciones decisivas para acercar el cese del conflicto interno, así como para preservar la integridad del territorio nacional. Si bien la Fuerza Aérea obedece a las directrices trazadas por el Gobierno a través del Comando General de las Fuerzas Militares, durante ese periodo la Fuerza Aérea inició su cuarto momento histórico. ${ }^{5}$ Su capacidad decisiva se demuestra con la diversidad en las operaciones que debió cumplir bien fuera por decisión gubernamental, o bien como respuesta inmediata ante los ataques del grupo ilegal usando grandes destacamentos, del mismo modo que cumplió la paciente labor de neutralizar a los cabecillas. Antes vale aclarar que es una victoria decisiva.

Parafraseando a Valencia (1998), los cuatro momentos de la Fuerza Aérea Colombiana serían: 1) la instauración en 1916 de la aviación militar en Colombia, que alcanza hasta la proyección del poder aéreo sobre Leticia (1932); 2) el decreto en 1942 de autonomía operativa bajo el nombre Fuerza Aérea Nacional. Entonces, a raíz de los pactos de seguridad con Estados Unidos durante la segunda guerra mundial, el país adquirió equipos y envió pilotos y mecánicos a especializarse en ese país; 3) la adquisición en 1969 de la flotilla de helicópteros UH-1H, junto con aviones Mirage-5 el año siguiente, que reflejaron más las necesidades del país desde entonces; 4) la nueva proyección de poder aéreo desde 1998, que en parte se analiza en este capítulo. 
Según Gray (2002) el concepto victoria decisiva exige ciertas precisiones, una de ellas es ratificar que el uso de la fuerza militar es un instrumento de decisión usado por los estados, aunque su resultado no siempre es la decisión esperada (Gray, 2002, p. 9). Otra precisión es que la victoria decisiva en lo militar conduce a decisiones políticas, en cualquier caso, considerando una gama de opciones aceptables. Ejemplo de lo primero es que con el conflicto interno se decidió que Colombia es un estado-nación que puede existir por sí mismo (Bushnell, 1994). Ejemplo de lo segundo, es que desde 1998 el grupo ilegal venía sufriendo derrotas militares y su dirigencia no lo consideraba una derrota decisiva, pero en 2012 aceptó dialogar.

En este sentido la victoria decisiva puede manifestarse en tres niveles (GRAY, 2002, p. 11): a) el operacional, cuando la victoria decide el resultado de una campaña, p. ej. la 'Operación J.M.' (2003-2005); b) a nivel estratégico, cuando la victoria decide quién gana en lo militar, p. ej. la serie de operaciones exitosas que llevaron a debilitar al grupo y sentarse a dialogar; c) la victoria decisiva a nivel político, es la que se negoció en La Habana.

Pese a lo anterior un desafío para este capítulo fue cómo construir historia militar y sobre un período inmediato. Siguiendo a KeEgAN (1995) sería inconcebible afirmar que en Colombia ha habido guerra, en cuanto ese autor sostiene que: "El desierto, la tundra, las selvas tropicales y las grandes cordilleras son inhóspitas al soldado y al viajero. El intento de combatir en terreno sin agua o sin carreteras es imposible y cuando en tal terreno se llega al combate suele tratarse de escaramuzas entre tropas especializadas muy bien equipadas" (p. 9798). Así este criterio nos ubica cómodamente en el concepto de conflicto interno. Pero dado que, en Colombia, durante los diferentes períodos del conflicto, el peso principal de neutralizar a los grupos armados ilegales correspondió a las Fuerzas Militares sería inicuo soslayar un enfoque de historia militar.

Si en un debate disciplinar, entre narrar acontecimientos o analizar estructuras, triunfó lo segundo, también se abrió paso la Nueva Historia de las Batallas. Destacado exponente de esta, KeEgAN (1990) al afirmar que los ejércitos se crearon para combatir, enfatizó que la historia militar debe tratar sobre las batallas. Y continúa, porque es a través de lo que los ejércitos hacen, es decir, "ganar o perder batallas- como se cambian las vidas de las naciones y de los individuos" (KeEGAN, 1990, p. 40). Allí mismo advertía también contra la retórica de la historia, un peligro para el historiador (sobre todo en Colombia), donde solo importa lo que hicieron (o dijeron) los generales, los oficiales y los políticos, obviando la experiencia colectiva.

No obstante, KEEGAN impone otra salvedad para una historia de las batallas en Colombia, al afirmar que en los conflictos tercermundistas la experiencia de los soldados no es en batalla: "Porque hay una diferencia fundamental entre 
el tipo de escaramuza esporádica y a pequeña escala que es como la pequeña caldera del soldado y lo que entendemos como una batalla. Una batalla debe obedecer las unidades dramáticas de tiempo, lugar y acción." (KeEGAN, 1990, p. 26) Excluye así a la principal característica de la táctica de guerrillas usada por los grupos armados ilegales: rehuir el combate, mientras realizan un constante desgaste o golpes de mano.

En consecuencia, aquí, reivindicamos una historia de los combates, primero, porque como parte de su misión constitucional las Fuerzas Militares no pueden rehuir el combate con tales grupos; de hecho, el gobierno les impuso perseguirlos y responder a sus aleves ataques ${ }^{6}$. Segundo, porque el combate irregular, análogo a las batallas, supone un conflicto de voluntades y debe conducir a una decisión, ${ }^{7}$ la derrota del otro en uno de los niveles citados arriba con GRAY (operacional, estratégico o político). Pero al reivindicar los combates se interpone otro desafío metodológico, que trasciende la esencia del conflicto colombiano: cómo construir historia (pasado) de un acontecimiento vigente (presente). La dificultad para el historiador sería que no conozca todos los efectos de los acontecimientos (SAUVAGE, 1998, p. 66).

Por lo anterior, este capítulo debió orientarse como una historia del tiempo presente (o historia inmediata). Es decir, aceptó la necesidad de explicar el presente dada la aceleración de la historia. Siendo que la misma vigencia del conflicto impide consultar y/o exponer fuentes confidenciales, primero recurrió a las fuentes publicadas aceptando el debate socio-político sobre la historia (Barros, 2006, párr. 14). Al respecto KEEGAN sugería dos técnicas: primera, reconstruir la experiencia humana en la batalla (e. g. el combate -Espino, 2001, p. 165), improbable por la restricción de fuentes acotada y solo promisoria a futuro con la tendencia reciente de memoria histórica. La segunda opción, fue la asumida aquí en lo metodológico, inicialmente al seleccionar los combates que militares y académicos coinciden en considerar decisivos; luego, presentar someramente los contextos, el geográfico y el político, en los cuales se produjeron; después, describir el combate en sí y, por último, un balance de sus resultados ${ }^{8}$.

$6 \quad$ Son los gobiernos quienes deciden cómo emplear la Fuerza Pública: "Con los decretos 1268 (abril 18) y el 1362 (abril 29) de 1948, se asignaron a las Fuerzas Militares funciones de policía, debido al licenciamiento total del personal de la Policía (...) Desde entonces las Fuerzas Militares de Colombia no han regresado a sus cuarteles porque se les ha ordenado combatir" (...) a los diferentes grupos armados ilegales y al crimen organizado (EsquIVEL, 2001. p. 123).

7 Una salvedad adicional aplica a nuestro caso de estudio: "Las misiones de combate de la FAC no necesariamente involucran la entrega de armamento; por ejemplo, una aeronave C-130 puede realizar una misión de combate cuando transporta tropas como parte de la maniobra militar para neutralizar las amenazas, o una aeronave de comando y control realiza misiones de combate para dirigir las acciones bélicas en el campo de batalla." (FAC, 2013, Manual, p. 79).

8 Dicho autor describe cada batalla "a fragmentos" (KeEGAN, 1990, p. 89), entre otros incluye según el caso: Campo de batalla; El Plan; La preparación; El Ejército; Las tácticas; El bombardeo; Preliminares finales; La batalla; Infantería vs. Ametralladoras; Los heridos; Motivación para combate. 
Para cumplir lo anunciado aquí se analizarán seis operaciones decisivas, entre 1998 y 2014, encuadradas en tres ciclos de la evolución de la Fuerza Aérea Colombiana9. En un primer ciclo, de 1998 a 2003, cuando confluye un proceso de reforma con la adopción de una doctrina conjunta que incluye las operaciones 'Vuelo de ángel' y 'Delta'. Un segundo ciclo, de 2003 a 2008, reflejo de una política gubernamental ofensiva cuyo mayor desarrollo fue el bombardeo de precisión, incluye las operaciones 'Universal' y 'Aromo'. Desde 2009 hasta el presente, un tercer ciclo, donde la Fuerza Aérea realiza el esfuerzo principal al tiempo que se activan más unidades conjuntas, incluye las operaciones 'Sodoma' y 'Odiseo'. Al final, un balance de las seis operaciones magnifica la capacidad decisiva de la Fuerza Aérea por cuanto simultáneamente cumplió cientos de misiones de aplicación de la fuerza y de control del espacio aéreo.

\section{REFORMA DE LA FUERZA PÚBLICA Y NUEVO ENFOQUE OPERATIVO (1998-2003)}

La naturaleza del conflicto armado interno en Colombia fue mutando en cada uno de sus períodos, ${ }^{10}$ transcurridos entre el siglo XX y el XXI, es decir que variaron tanto sus causas como sus actores de origen político y delincuencial (Sánchez, 2009, p. 23). Tal mutación reflejó un cambio progresivo en los esfuerzos nacionales para resolver el conflicto y, por ende, estimuló un ajuste en el modo de operar de la Fuerza Aérea. La escasa historiografía sobre la Fuerza Aérea en el conflicto colombiano describe el cambio desde un ocasional suministro de apoyo aerotáctico al Ejército Nacional, en operaciones de contra-guerrilla (VILLALOBOS, 1993, p. 246, 336), hasta el permanente alistamiento para operaciones conjuntas y de combate directo (FAC, 2005, p. 184).

Desde el primer período del conflicto interno en Colombia hasta 1998, el gobierno incrementó esporádicamente sus recursos para contener ${ }^{11}$ a los grupos

9 Sobre el período previo el suscrito autor preparó en 2016 otro análisis cuya referencia sería: EsQuiveL, R. (2017). Transformación aerotáctica y conflicto en Colombia, 1985-1998. Boletín de Historia y Antigüedades, 864.

10 Del conflicto armado interno en Colombia se dice que un primer período fue 1930-1932, con foco entre Soatá y Málaga (Guerrero, 1991); un segundo, bajo el eufemismo 'La Violencia', fue 1948-1957, con focos en los Andes centrales y Llanos Orientales; el tercer período, lo inició el MOEC, de Tulio Bayer, en 1961 (Sánchez y Peñaranda, 1997; Valencia, 1992). Este último ahora se subdivide en tres períodos: el primero, va hasta 1982, origen de grupos armados ilegales de izquierda (FARC, ELN, EPL) y de derecha (M-19); el segundo, 1982-1996, donde los anteriores grupos subsumen al narcotráfico y surgen grupos armados de extrema derecha (Autodefensas ilegales); un tercer sub-período, 1996-2005, de "guerra contra la sociedad" (parafraseando a Pecaut, 2001). No obstante, citando el Protocolo 2 de Ginebra (1948) y dadas sus ínfimas cifras, se dice que no hubo conflicto ni guerra entre 1961-1982 (González, 2013, p. 11). Más variantes sobre esta caracterización del conflicto en Comisión Histórica (2015), aunque allí no se diferencia entre la historia del país y la del conflicto.

11 Se afirma que "El crecimiento [del Ejército] obedeció a una concepción estratégica de contención, bajo el eufemismo del 'control del orden público'.” (Santos, J., 2002, p. 51) 
armados ilegales. Incluso durante la década de 1990 cuando se intensificó el conflicto, las Fuerzas Militares pasaron de tener aproximadamente un número de 139.000 efectivos en 1992 a 146.000 en 1998, es decir, un incremento solo del 5\%. Aún sobre el número más alto, entonces, las Fuerzas Militares poseían una escasa superioridad de 2.3 a 1 frente a los grupos ilegales ${ }^{12}$ (EsQuiveL, 2001, p. 125).

La Fuerza Aérea, durante esa década de 1990, tampoco tuvo un incremento significativo excepto por la adquisición en 1992 de aviones de instrucción y en 1993 de helicópteros livianos y pesados (43 Hughes, 23 Bell, 8 UH-60). Otras adquisiciones vinieron después en el marco del Plan Colombia, cuyo presupuesto se aprobó en julio del 2000 por el Congreso de EE.UU., enfatizando la lucha contra el narcotráfico y el fortalecimiento de la Policía Nacional.

No obstante, en diciembre de 1998, la recuperación de Mitú fue un hecho que alteró la naturaleza del conflicto al evidenciar la capacidad decisiva de la Fuerza Aérea para derrotar a los grupos armados ilegales en su intención de desestabilizar al país. Tal capacidad empezó a desarrollarse progresivamente en medio del debate entre dos enfoques doctrinarios: uno, que además de imitar a EE.UU. se ajustaba a las imposiciones de la guerra fría; otro, que intentaba responder a las necesidades nacionales frente al conflicto (helicópteros, no caza bombarderos), al desarrollo de las regiones atrasadas (Satena) y responder a desastres.

La acción decisiva de la Fuerza Aérea en Mitú sobrevino justo cuando el gobierno iniciaba diálogos de paz con el grupo armado ilegal, lo que incrementó el impacto positivo de la acción sobre la solución negociadora. Los diálogos se prolongarían durante más de tres años, sin cesar las hostilidades y mientras la Fuerza Pública consolidaba una reforma para adecuarse al conflicto.

Esta reforma para un nuevo período de conflicto, se intensificó simultáneamente con el inicio del gobierno Pastrana y luego con el llamado Plan Colombia. EE.UU. suministraría a Colombia armas y entrenamiento para combatir el narcotráfico, mientras el gobierno colombiano adelantaría programas de desarrollo alternativo con fondos propios y europeos. Dada la urgencia de fortalecer a la Fuerza Pública, en particular sus capacidades contra los grupos ilegales, el Plan Colombia adquirió mayor relevancia. La capacidad de la Fuerza Aérea, contra el narcotráfico y contra los grupos ilegales, sería decisiva en el conflicto.

La recuperación de Mitú inauguró un cambio en la forma de operar la Fuerza Aérea, sin abandonar su misión de asegurar el espacio aéreo colombiano, ${ }^{13}$ un

\footnotetext{
12 Según las teorías vigentes la ventaja debería ser 10 a 1 para derrotar a los grupos armados ilegales; súmese a esa deficiencia que Colombia, distraída en el conflicto interno, tenía una desventaja de 24,5 a 1 para defender su territorio de los vecinos, como se explica en EsQuiveL, 2001. pp. 124-128.

13 La recuperación de Mitú también figura como la primera de la serie de operaciones exitosas de la Fuerza Pública que desde entonces incluyeron las de: Puerto Rico y Puerto Lleras (julio 1999); Hato
} 
logro que fue aprovechado en siguientes operaciones o que llevó a desarrollar nuevos desarrollos tácticos y tecnológicos. La Fuerza Aérea desplegó nuevas unidades, incorporó nuevas tecnologías, recibió nuevos equipos, adaptándose más a las condiciones de guerra asimétrica donde la velocidad, la sorpresa y la precisión superan las tácticas de guerrilla de los grupos armados ilegales. La neutralización del máximo cabecilla del grupo ilegal FARC, en noviembre de 2011, confirmó la efectividad de la Fuerza Aérea para hacer valer el control del territorio nacional por el gobierno.

\section{Operación Vuelo de Ángel (Mitú-Nov. 1998) ${ }^{14}$}

Campo de combate: El departamento del Vaupés, con $54.135 \mathrm{~km} 2$, es uno de los más extensos de Colombia y es más grande que países como Costa Rica o Suiza. Hace parte de la reserva forestal de la Amazonia, en la zona de transición entre los llanos de la Orinoquia y la selva amazónica; cubierto en gran parte por bosques, con clima húmedo tropical y temperatura media de 27 grados centígrados. El departamento está habitado por unas 27 etnias indígenas pertenecientes a las familias lingüísticas Makú, Arawak y Tukano, que representan $85 \%$ de la población del departamento. Su densidad poblacional es de 1,35 habitantes por kilómetro cuadrado sumando Mitú, la mayor concentración de población, y los demás municipios; a su vez, el $37 \%$ de la población se ubica en zonas urbanas.

La población indígena del Vaupés se ha readaptado según los sucesivos embates de la extracción de recursos: entre fines del siglo XIX y mediados del siglo XX, la del caucho. Desde la década de 1950, la explotación de maderas y especies exóticas. Desde la década de 1970, el auge del narcotráfico, impactando el crecimiento urbano de Mitú y Carurú. Desde la década de 1980, el oro superpuso otra ola de explotación que mantuvo a Mitú como centro de comercialización. No obstante, el control del cultivo y de la producción de base de coca lo ejerció el grupo ilegal, primero sobre el Alto Vaupés y luego sobre el resto del departamento (ACNUR, 2007, p. 7).

Mitú es la capital del departamento del Vaupés, un municipio con cerca de 7.000 habitantes, ubicada a $200 \mathrm{~m}$. de altitud sobre la margen derecha del río Vaupés, en la frontera con Brasil. Aunque en 1936 fue erigido el poblado, en parte para reafirmar la presencia colombiana frente a la influencia brasilera (PEÑA, 2011, p. 70, 81), hace apenas unos 40 años fue reconocido como municipio. Esa lenta evolución es atribuible tanto a la baja densidad poblacional como a su ubicación.

Corozal (agosto 1999); 'Berlín' (Santander, noviembre 1999); San Juan de Sumapaz (2000); ‘Gato Negro' (Vichada, febrero 2001); 'Tsunami’ (Nariño, mayo 2001), según El Tiempo (2001, agosto, p. 1-17).

14 La reconstrucción de esta Operación y de las demás en este capítulo sigue fuentes secundarias. Para el caso 'Vuelo de Ángel' las fuentes, aun las de miembros de la Fuerza Aérea, todas divergen en los detalles de cómo ocurrieron los hechos; para mayor objetividad el libro incluye sobre las mismas operaciones más descripciones realizadas desde otras disciplinas. 
El municipio constituye un resguardo indígena, excepto el área del casco urbano $(5 \mathrm{~km} 2)$. Fue un asentamiento ancestral de la etnia Cubeo, pueblo de la familia Tukano, sobre el cual intervinieron sucesivas misiones clericales. Ya en el siglo XX jesuitas y monfortianos indujeron la concentración de población en Mitú, convirtiéndose el municipio en polo de atracción de las comunidades indígenas para interactuar entre sí y con los servicios del Estado, como tal una expresión de democracia y de identidad colombiana en la Amazonia (Peña, 2011, p. 186).

Mitú está aislado del centro de Colombia. Por vía carreteable solo puede conectarse con la localidad de Monforth, a $54 \mathrm{~km}$ de distancia; aunque hay una extensa red de caminos que conectan a las comunidades del departamento. Tampoco es muy accesible por vía fluvial con el interior del país, dado que el río Vaupés abunda en raudales que limitan la navegabilidad. Desde el municipio de Carurú hasta Mitú el viaje puede tomar dos días. Por el mismo río Vaupés, que sirve de línea fronteriza con Brasil, desde Yabaraté toma unas 24 horas para llegar a Mitú; así como el río se conecta con el río Negro y el Amazonas.

Por lo anterior la vía aérea se convirtió en la principal forma de acceso. La pista aérea de Mitú se remonta a la década de 1920, la que años después se amplió reorientándola en sentido norte-sur, en ambas ocasiones por iniciativa de las misiones clericales. Al efecto cuenta con el servicio de vuelos nacionales de Satena y de servicios de carga regionales que cumplen otras aerolíneas (Alcaldía de Mitú, 2015).

Mitú es así un municipio importante, además del hecho de ser una capital de departamento, por reunir tres atributos relevantes para el futuro del país: uno, ser el polo de desarrollo de los resguardos indígenas alrededor; dos, ser un municipio expresión del dominio colombiano de la Amazonia y, tres, por ubicarse en la frontera con Brasil.

Preparación: Ya en 1986 se registró un hostigamiento del grupo ilegal contra el cuartel de policía en Mitú, a la par con las exacciones contra la población. A partir de 1993 se incrementó la presión del grupo sobre la población a través del reclutamiento forzoso, el desplazamiento forzado, el tributo al cultivo de coca y la cooptación del aparato político local (Vicepresidencia de la República, 2003, p. 7).

Desde abril de 1996, con el ataque en Puerres (Nariño), el grupo venía realizando acciones ofensivas contra poblaciones y unidades militares aisladas, para dispersar los recursos de las FF.MM. y pasar de la guerra de guerrillas a la de movimientos ${ }^{15}$.

15 MAO en su teoría de guerra popular prolongada aludió a tres etapas según la correlación de fuerzas, para las propias: defensiva estratégica; 'preparación' para la siguiente y, esta, la contraofensiva estratégica. Aparte aludió a tres "formas de lucha": de guerrillas, de movimientos y de posiciones (1968, p. 176). Aplicadas a su país en 1937, donde fuerzas regulares chinas resistían la invasión de fuerzas regulares japonesas, subrayó que la guerrilla (golpea y huye) era un auxiliar y usada eventualmente por campesinos en cualquier etapa. El grupo ilegal FARC se inició en forma de guerrilla según el 
Si bien, a partir de acciones similares en Las Delicias y El Billar, las Fuerzas Militares pudieron reaccionar ante estos ataques con mayor rapidez, cantidad y calidad del apoyo aéreo; así como con planes "mucho mejor estructurados" (Pardo, 2004, p. 546). No obstante, en 1998, la seguridad en Mitú era cubierta por 90 efectivos de la Policía Nacional, más 30 auxiliares bachilleres indígenas.

A mediados de 1998 inició el nuevo gobierno elegido por los colombianos, que presidía Andrés Pastrana. Este acordó, conforme a su campaña electoral, realizar diálogos de paz con el grupo ilegal FARC en una zona de distensión ${ }^{16}$. No obstante, el grupo ilegal persistiría en sus acciones armadas, según informe que difundió su dirigencia dos días después del ataque a Mitú (Semana, 1998, Diciembre, párr. 1). El ataque contra Mitú fue el tercero del grupo en 1998, en marzo lo hizo contra la Brigada Móvil 3 en El Billar y, en agosto, se tomó la base antinarcóticos de Miraflores auspiciada por Estados Unidos (Martínez, 2006, p. 288).

El combate: El domingo 01 de noviembre de 1998, pasadas las 4:00 de la mañana, unos 600 efectivos del grupo ilegal Farc (Restrepo, 1999) atacaron el municipio de Mitú $^{17}$. Siendo los blancos principales el cuartel de Policía, la Caja Agraria y la pista de aterrizaje, también fueron objeto de ataque entre otros los edificios de la Registraduría, los juzgados, las sedes de Telecom, la Escuela de Administración Pública, la Fiscalía y el Vicariato. Al efecto el grupo empleó, además de fusiles, ametralladoras M-60, lanzagranadas MGL-40 mm, morteros $60 \mathrm{~mm}$ (Radio Santafé, 2015), armas no convencionales ${ }^{18}$. Hacia las 16:30 el grupo logró tomar el casco urbano. Al parecer, el grueso del grupo se desplazó por el río Vaupés, pasando por Miraflores (Guaviare) donde meses antes se desalojó a la Fuerza Pública (MOE, 2010, p. 6). El control de Mitú fue recuperado por la Fuerza pública al cabo de 72 horas.

En el Comando General de las Fuerzas Militares, considerando que Mitú era inaccesible por tierra y que la pista del municipio estaba controlada por el contrincante, se decidió lanzar una operación aérea desde San José del Guaviare. Este municipio, capital del departamento de Guaviare, está ubicado a 180 millas (300 km) de Mitú. En consonancia, el Comando de la Fuerza Aérea ordenó

modelo cubano del 'foco' y en, la acepción maoísta, la etapa defensiva. En 1982, por decisión de sus cabecillas, habría pasado a la etapa de 'preparación' por incremento de efectivos, así que agregaron el 'Ep' (ejército del pueblo) a su nombre (CNMH, 2013, p. 114). Apenas en 1993 plantean desarrollar una guerra de movimientos, o sea, concentrar sus efectivos para golpear a la Fuerza Pública. En este intento fue que el grupo fracasó y ahora está sentado en la mesa de negociación.

16 Más detalles sobre esta zona en el apartado siguiente de este capítulo.

17 Otras fuentes mencionan hasta 1.500 efectivos del grupo ilegal. Aquí se prefiere la cifra más conservadora de 600 efectivos, porque aun así daría una ventaja a los atacantes de 6 a 1 contra los 90 policías de Mitú; también, porque no obtuvimos evidencia que respalde ninguna cifra.

18 P. ej. lanzar pipetas de combustible, unas rellenas con gasolina y otras con explosivos y metralla. 
coordinar la operación a la Base Aérea de Apiay (CACOM 2) ${ }^{19}$ ubicada a 270 millas (490 km.). Para la operación en Mitú, la Fuerza Aérea empleó aviones de transporte táctico $(\mathrm{CN}-235)$ y pesado $(\mathrm{C}-130)$, aviones de ataque y combate AC47T, AT-27, OV-10 y A-37, aeronaves de ala rotatoria utilitarios UH-60 y artillados AH-60 (FAC, 2005, p. 200; Pardo, 2004, p. 543). No obstante, los helicópteros no tenían autonomía para ir y regresar hasta Mitú (véase tabla 1).

Tabla 1. Distancias otros municipios y Mitú.

\begin{tabular}{|l|l|l|r|}
\hline \multicolumn{1}{|c|}{ Distancia } & \multicolumn{1}{c|}{ Millas } & \multicolumn{1}{c|}{ Distancia } & \multicolumn{2}{c|}{ Millas } \\
\hline Apiay a San José & 100 & San José a Mitú & 180 \\
\hline Apiay a Mitú & 270 & San José a Querarí & 31 \\
\hline Apiay a Querarí & 290 & Mitú a Querarí & 336 \\
\hline
\end{tabular}

Fuente: Elaboración propia.

Hacia las 6:15, desde la base de Apiay se envió un avión AC-47T (popularmente llamado 'Fantasma') para apoyar a los policías que resistían el ataque; este llegó a Mitú hacia las 7:40. Veinte minutos antes, habían llegado dos aviones OV10 Bronco para realizar bombardeo contra los atacantes. El segundo AC-47T, proveniente de la base de Tres Esquinas, llegó a las 8:45 para relevar al primero (FAC, 2005, pp. 193-194).

Eran las únicas “aeronaves que tenían capacidad de vuelo para llegar a Mitú y sostener combates durante tres o cuatro horas (...). Las tripulaciones harían contacto directo con el Comando de Policía de Mitú y así conocerían el lugar desde donde los atacaban y analizarían la situación para planear los apoyos.” (MARTínez, 2006, p. 291) Para asegurar las comunicaciones, desde Apiay se envió un avión T-27 para que sobrevolara a 22.000 pies de altura, entre San José del Guaviare y Mitú.

No obstante, fue casi imposible que las aeronaves usaran su armamento. Los pilotos al establecer contacto radial con el cuartel de policía, fueron alertados que los atacantes disparaban desde el hospital y desde una escuela, sin precisar donde se ubicaban. El cuartel mismo estaba rodeado de viviendas civiles, desde

19 Comando Aéreo de Combate-CACOM. La Fuerza Aérea comprende seis de estos comandos, con base en Puerto Salgar CACOM 1, en Apiay CACOM 2, en Malambo CACOM 3, en Melgar CACOM 4, en Rionegro CACOM 5, en Tres Esquinas CACOM 6; también cuatro Grupos Aéreos, con base en Leticia GAAMA, en San Andrés GACAR, en Yopal GACAS y en Marandúa GAORI. Además cuenta con el Comando Aéreo de Transporte Militar -CATAM, en Bogotá y el Comando Aéreo de Mantenimiento -CAMAN en Madrid. 
donde otros miembros del grupo disparaban. Una dificultad adicional es que no había información cartográfica sobre Mitú. En Apiay se recurrió a un policía, que sirvió en Mitú, para levantar un croquis del casco urbano ${ }^{20}$. Este se entregó al primer relevo de pilotos enviados al municipio sitiado; cada tripulación que regresaba ayudó a perfeccionar el croquis.

Otra dificultad para la operación aérea fue disponer de una zona de aterrizaje cercana a Mitú. Sin olvidar que los aviones de transporte y los helicópteros no tenían autonomía de vuelo para viajar hasta el municipio y regresar. Otras poblaciones del departamento no tenían la seguridad adecuada para las aeronaves y las tropas. La única opción fue una pista al otro lado de la frontera, en Querarí, un puesto de vigilancia del ejército brasilero en el vecino municipio de São Gabriel da Cachoeira ${ }^{21}$, a $56 \mathrm{~km}$ de Mitú. Pero tampoco había información disponible sobre las especificaciones de la pista, así que se envió un AC-47T para hacer reconocimiento, confirmar las coordenadas y tales especificaciones.

A través del Comando de la Fuerza Aérea se gestionó un permiso diplomático. El gobierno Pastrana invocó razones humanitarias para que Brasil permitiera establecer un puente aéreo, así reabastecer las aeronaves y evacuar los heridos. Mientras se obtenía el permiso, la Fuerza Aérea coordinó en Apiay la concentración de los aviones de combate y transporte, como los equipos de tanqueo FARE, ${ }^{22}$ provenientes de todo el país. Se solicitó a la base antinarcóticos de la Policía en San José del Guaviare encargarse del suministro del combustible JP4 hasta Querarí. También en San José, la Fuerza Aérea reunió personal técnico, controlador aéreo, armamento, helicópteros y aviones.

En Apiay, se concentraron los primeros 120 soldados, con 6 helicópteros UH60 y 2 helicópteros AH-60L (Arpía) ${ }^{23}$. A las 14:55 fueron enviados hacia San José para esperar la autorización brasilera, a su vez tendrían que esperar en Querarí a que el aprovisionamiento de combustible estuviera listo. Hacia las 16:00 horas se recibió la autorización de Brasil para usar la pista de Itibare, setenta millas al sur y por tiempo limitado; minutos después el grupo ilegal lograba copar el municipio.

A esta misma hora el primer C-130 (Hércules), con 100 soldados, y un CN-235 Nurtanio, el cual trasportaba tres tanques de gasolina (cerca de 1.500 galones),

$20 \quad$ El croquis se anexa en otro capítulo de este libro.

21 Del lado brasilero, hacia 2003, se contaban 10 bases dependientes del Comando Militar Amazónico con sede en Manaos. Este incluye tropas de infantería de selva, ingenieros, un comando naval y dos aéreos, además de la Policía Federal (Vicepresidencia de la República, 2003, p. 15). Existe un acuerdo de seguridad entre los gobiernos de Colombia y Brasil, que facilita la colaboración en la zona.

22 FARE: Forward Air Refueling Equipment, un equipo de reabastecimiento de combustible en áreas remotas.

23 Los helicópteros UH-60 (Black Hawk) son dotación en la Fuerza Aérea y en la Aviación del Ejército. Pueden ser para transporte de tropa (UH-60L) o artillados para combate (AH-60L, Arpía) con dos ametralladoras .50 y lanzacohetes (MARTíNEZ, 2006. p. 296). 
partieron de Apiay hacia San José. A mitad de camino se les ordenó dirigirse a Querarí, para arribar hacia las 17:30 horas, una vez reiterado el trámite ante Brasil. El C-130 fue el único enviado, la pista resultó más angosta y corta de lo que sus señales oficiales indicaban. En adelante, el transporte tuvo que hacerse en aviones $\mathrm{CN}-235$, con capacidad solo para 50 soldados. Mientras, hacia las 17 horas, el AC-47T que sobrevolaba Mitú perdió comunicación radial con el cuartel atacado. Su tripulación pudo observar impotente como el grupo ilegal sacaba a los policías del cuartel y los conducía hacia embarcaciones a la orilla del río.

A las 17:30, desde San José partió una escuadrilla de 7 helicópteros, 5 UH60 y 2 AH-60L, con 172 soldados del Batallón de Contraguerrilla 52 y 20 policías del Grupo Jungla. La mayoría de soldados de aquella unidad habían sufrido el ataque del grupo ilegal en El Billar; luego de pasar una temporada de reentrenamiento estaban dispuestos a cambiar su suerte. La orden era realizar un asalto aerotransportado en cercanías a Mitú, pero la noche llegó antes y dado que solo el helicóptero líder disponía de visores nocturnos, la escuadrilla debió seguir a Querarí (FAC, 2005, p. 195).

Considerando que en la selva la oscuridad es total, hacia las 18:00 se ordenó al AC-47T volar sobre Querarí para lanzar bengalas que iluminaran la aproximación de los helicópteros a la pista. Las aeronaves y la tropa enviada a Querarí, debieron pernoctar allí. Sin agua, sin comida, las tropas del Ejército sin comunicación radial y el equipo para bombear el combustible falló. A pesar de la falta de información precisa, a las 21:00 horas se realizó un pre-briefing ${ }^{24}$ decidiéndose improvisar los puntos de desembarco bajo la escolta de los helicópteros AH-60L.

De regreso el AC-47T, en la oscuridad, pudo detectar los movimientos del grupo ilegal mientras aseguraban el control en Mitú. Se procedió a neutralizar con efectividad suficiente para causar grandes bajas entre el grupo (Martínez, 2006, p. 302). Entre tanto en Apiay, arribaron un avión C-130, dos CN-235 provenientes de CATAM, en Bogotá, y un AC-47T desde la base de Palanquero (Perea \& Murcia, 2014, p. 31).

El lunes 02 de noviembre, siendo las 03:20 horas, un avión C-212 salió de la base de Tres Esquinas (Caquetá) hacia Querarí llevando equipos FARE y dos operarios para los mismos. Entre las 03:50 y 4:50 de la mañana partieron desde la base de Apiay hacia Querarí dos aviones CN-235 llevando combustible y alimentos. Hacia las 4:30 el AC-47T, los dos OV-10 y el T-27 reiniciaron sus operaciones. En Querarí, a las 5:30 horas se cumplió el suministro de agua y raciones para los 270 soldados concentrados allí, como fue reabastecido de combustible el componente aéreo táctico de la Fuerza Aérea.

$24 \quad$ Briefing: anglicismo que denomina una reunión previa al vuelo, donde se detallan los aspectos de la misión a cumplir y se verifican algunos procedimientos tácticos. 
La gestión diplomática ante Brasil logró una autorización solo para operar entre las 9.00 y las 15:00, hora colombiana. Así, desde la primera hora dos AH60L hicieron selección de campos y ablandamiento; posteriormente, los cinco UH-60 desembarcaron las tropas en lugares asignados a 7 kilómetros de Mitú, siempre escoltados por los $\mathrm{AH}-60 \mathrm{~L}$ y por un $\mathrm{AC}-47$ a mayor altura. "El enemigo fue detectado a las 09:45 horas por un Arpía, los UH-60L artillados procedieron al ataque." (Perea \& Murcia, 2014, p. 33) A las 11:30 horas terminó la primera fase de desembarco, 250 soldados.

Una hora y media después inició el combate en tierra con el grupo ilegal, los helicópteros no pudieron dar apoyo por falta de combustible, así que solo el AC-47T y los OV-10 pudieron proveer cobertura. El grupo ilegal había montado 35 puntos de emboscada contra las tropas, que resultaron en la muerte de 16 efectivos del Batallón 52 y 4 policías, así como heridos 30 militares y 4 policías. Mientras el Comando del Ejército insistió en que debían reforzarse las tropas así como evacuar los heridos y muertos, lo que se cumplió durante el resto del día y la noche transportándolos respectivamente al Hospital Militar en Bogotá o a Villavicencio.

Una vez vencida la autorización brasilera, desde Querarí regresaron a San José 4 helicópteros de transporte UH-60. De igual modo, los CN-235 regresaron a San José y Apiay con los equipos FARE. Así que las tropas que combatían sobre Mitú solo quedaron con el apoyo del AC-47T, con sus equipos de monitoreo, y de los OV-10, con visores nocturnos y radios con seguridad de voz (Martínez, 2006, p. 304); sin mayor descanso para las tripulaciones. Hacia las 17:00 horas, las tropas en tierra iniciaron un repliegue defensivo; a la misma hora que Brasil otorgó una nueva autorización para usar la pista de Querarí por 24 horas.

La autorización no fue informada a la base de Querarí, así que cuando a las 21:00 arribó un CN-235 proveniente de San José con combustible, los brasileros retuvieron a la tripulación de la aeronave ${ }^{25}$. Aclarada la confusión, a las 22:00 horas, helicópteros con visores nocturnos salieron de San José con otro grupo de soldados hacia Querarí; les siguieron tres aviones CN-235, volando solo por instrumentos. Entonces no todas las tripulaciones disponían de visores nocturnos, debido a que Estados Unidos restringió el suministro de ayudas a la Fuerza Aérea durante el gobierno Samper (MARTínEZ, 2006, p. 304).

El martes 03, el grupo ilegal comenzó a huir. Ese día, de madrugada, el AC-47T detectó con su sistema FLIR a miembros del grupo que huían por el río, neutralizó a varios de ellos y les hundió una embarcación. En conjunto,

25 Según Brasil las operaciones colombianas en Querarí excedieron el carácter humanitario, las considero operaciones de guerra y violatorias de los tratados internacionales. Por ello el gobierno brasilero envió luego una protesta oficial a su homólogo colombiano. 
las aeronaves lograron destruir 17 embarcaciones (El Tiempo, 1998). Hacia las 8:00, el AC-47T detectó otra columna en movimiento y procedió a neutralizarla, causándole unas 80 bajas. El combate por el ingreso al casco urbano se intensificó desde el martes a las 16:00 y siguió hasta las 5:00 horas del día siguiente (Padilla, 1998). Al amanecer del miércoles 04 de noviembre, los primeros soldados entraron a Mitú. Cuatro manzanas a la redonda del cuartel de policía habían sido destruidas por el grupo.

Los balances: En el ataque del grupo ilegal contra Mitú resultaron 21 policías muertos y 10 heridos. Entre los civiles, 16 fueron muertos y otros 9 heridos. La recuperación del municipio por la Fuerza Pública se saldó con la muerte de 16 militares y 4 policías, heridos 20 militares y otros 4 policías. El grupo ilegal se llevó secuestrados 61 policías, entre estos los miembros del mando policial y 14 miembros indígenas. Los secuestrados fueron internados en campos de concentración en medio de la selva, algunos por más de trece años y otros finalmente muertos en cautiverio.

Pese a tan trágico saldo, la recuperación de Mitú es reconocida como un éxito de la Fuerza Pública. "La operación Vuelo de Ángel fue el resultado de un programa de readecuación de las Fuerzas Militares, que dio vuelta a una situación reiteradamente desfavorable."'(Pardo, 2004, p. 546) El propósito del grupo ilegal, iniciado agosto de 1996 en Las Delicias, de pasar a la guerra de movimientos se frenó en Mitú. Sus ataques en masa contra unidades de la Fuerza Pública, en el suroriente del país, pasaron a ser una desventaja ante la capacidad de reacción y de alistamiento de la Fuerza Aérea Colombiana.

\section{OPERACión DELTa (ZoNa DE DiSTENSIÓN-FEB. 2002)}

Entre el 7 de noviembre de 1998 y el 20 febrero de 2002, por decisión del gobierno Pastrana, funcionó una 'zona de distensión' que estuvo bajo control del grupo ilegal. Esta zona, además de prórrogas sucesivas, fue ratificada como prerrogativa presidencial por la Corte Constitucional (2001). No obstante, durante los más de tres años que se mantuvo, el grupo no solo prosiguió sus acciones armadas, sino que hizo de la zona una base del narcotráfico y otros delitos.

Campo de combate: La 'zona de distensión' incluyó cinco municipios, en detalle: La Macarena, Vistahermosa, Mesetas y La Uribe (estos cuatro del departamento del Meta), más San Vicente del Caguán (del departamento del Caquetá). Por ende, el Presidente ordenó a la Fuerza Pública retirarse de dichos municipios (El País, 2013), en suma, un área de $43.090 \mathrm{~km} 2$ (véase tabla 2). En particular el Ejército debió abandonar el cuartel del Batallón Cazadores, en San Vicente, y la Policía Nacional cada uno de sus cuarteles por municipio. 
Tabla 2. Municipios de la zona de distensión 1998-2002

\begin{tabular}{|c|c|c|c|c|c|}
\hline Municipio & La Macarena & Vistahermosa & Mesetas & La Uribe & San Vicente \\
\hline Extensión $\mathrm{km} 2$ & 11.200 & 4.900 & 2.000 & 7.116 & 17.874 \\
\hline $\begin{array}{l}\text { Habitantes } \\
\text { urbano/rural }\end{array}$ & $2.700 / 11.500$ & $6.200 / 11.100$ & $3.000 / 10.470$ & $967 / 9.300$ & $7.288 / 40.000$ \\
\hline Economía & Agrícola; ganadería & Agrícola; ganadería & Agrícola; ganadería & Agrícola; ganadería & Agrícola; ganadería \\
\hline $\begin{array}{l}\text { Producción } \\
\text { coca has./ kilos } \\
\text { x mes }\end{array}$ & $3.200 / 2.200$ & $950 / 600$ & $420 / 280$ & $800 / 540$ & $5.000 / 3.400$ \\
\hline Acceso & $\begin{array}{l}\text { Aéreo;río Guay- } \\
\text { abero }\end{array}$ & Carretera; río Güejar & Carretera; trochas & Trochas; río Duda & Carretera; ríos. \\
\hline Interconexión & $\begin{array}{l}\text { San Vicente del } \\
\text { Caguán, Guaviare }\end{array}$ & Granada & Uribe, Granada & $\begin{array}{l}\text { Caquetá, Huila, } \\
\text { Tolima, C/marca. }\end{array}$ & Huila, Meta \\
\hline $\begin{array}{l}\text { A t a q u e } \mathrm{s} \\
\text { grupo ilegal }\end{array}$ & 1977 & 1998 (marzo) & 1998 (marzo) & 1998 (agosto) & nd. \\
\hline
\end{tabular}

Fuente: Elaboración propia basada en Semana (1998, Octubre).

Otra particularidad de la zona de distensión es que estaba incrustada en el Parque Nacional Natural de La Macarena. Tres de los municipios de tal zona eran parte del parque, a saber, La Macarena, Vistahermosa y Mesetas. En particular Vistahermosa alberga una de las mayores concentraciones de cultivos de coca del país. ${ }^{26}$ Desde este municipio, siguiendo por el río Güejar que sirve al Parque como límite por el norte, se ubicaba una cadena de comercialización de la coca; todo controlado por el grupo ilegal (FIP, 2006, p. 3).

Aunque el Parque de La Macarena tiene tres sectores diferenciados, a saber: hacia el occidente, vegas de los ríos Duda y Guayabero; hacia el oriente, llanura selvática entre los ríos Güejar, Ariari y el Guayabero Sur. La Sierra de La Macarena, con alturas entre los 300 y los 2000 metros sobre el nivel del mar. Predomina el clima amazónico norte, o sea, de tipo tropical con dos estaciones: una de lluvias, de abril a noviembre, de carácter torrencial (entre 250 a $450 \mathrm{~mm}$ mes); una estación de sequía, de diciembre a marzo, con temperatura hasta de $30^{\circ}$ centígrados. Los ríos y quebradas son abundantes y bastantes caudalosos (GonZÁLEZ, 1990, pp. 120-122). Hasta aquí un medio geográfico en el cual no debería haber guerra al decir de KeEgAN (1995).

En esta área el foco decimonónico de la colonización fue La Uribe, desde 1951 el eje de poblamiento se trasladó a San Juan de Arama, el primer poblado que se fundó bajo el dominio español en los Llanos colombianos (ESQUIVEL, 2002). La Uribe pasó a depender de San Juan en 1959, igual que otros caseríos que nacen entonces alrededor del Parque Nacional, entre ellos Mesetas, Vistahermosa, La

26 En 2004, se estimó que en el Parque habían 2.707 Has. cultivadas y Vistahermosa se concentraba en Vistahermosa, según la UNODC (citado FIP, 2006, p. 5). 
Macarena y Puerto Rico (Meta). Entre 1979 y 1982 se produjo una avalancha de colonos en estos municipios, atraídos por el auge del cultivo de la coca, alterando los ecosistemas del Parque Natural (GonzÁLEZ, 1990, p. 129). Es en ese contexto que el grupo ilegal ganó influencia en el área.

Durante la vigencia de la zona de distensión, el grupo ilegal procuró extender su dominio atacando sistemáticamente los municipios colindantes. Así ocurrió en el departamento del Meta con Puerto Lleras, Lejanías, Puerto Rico, San Juanito, El Calvario, Mapiripán, Puerto Concordia (El Tiempo, 1999). Igual pretendió en el Tolima con Purificación, la Alpujarra, Villarrica, Icononzo, Algeciras y Roncesvalles, además de concentrar efectivos en Prado y Cunday. La intención era establecer un corredor desde el municipio de Colombia (Huila) hasta la zona de distensión, en límites con los departamentos del Cauca y el Valle, para facilitar los tráficos ilegales hacia el Pacífico (El Tiempo, 2000).

A julio de 2000, unos 24 municipios alrededor de la zona de distensión habían sido hostigados regularmente. En consecuencia, la Policía se retiró paulatinamente de esos municipios. En el Departamento del Caquetá, entre ellos El Doncello, Puerto Rico, El Paujil y Cartagena del Chairá, así como los corredores viales que conectaban estos municipios con San Vicente, Montañita y Florencia (Colprensa, 2013).

La preparación: Al establecerse en 1998 la zona de distensión por orden presidencial, la Fuerza Aérea determinó que el Escuadrón de Reconocimiento debía prepararse para asumir el control aéreo de tal zona. Durante la década anterior este Escuadrón había fortalecido sus capacidades para, entre otras, realizar aerofotografía, fotointerpretación, monitoreo de señales de radio HF y VHF; así como recibió un avión Súper King B-300 equipado como plataforma de inteligencia de señales. Precisamente el reconocimiento aéreo se convirtió en un medio para vigilar las actividades del grupo ilegal en la zona de distensión; misión que progresivamente debió incrementar sus horas de vuelo y el volumen de información al respecto (Esina, 2014).

Cuando en febrero de 2002 el gobierno Pastrana decidió recuperar el control sobre los cinco municipios, debió sopesarse que en los planes del Ejército Nacional se preveían seis meses para lograrlo. Por su parte, la Fuerza Aérea preveía en su planeamiento facilitar el ingreso de las tropas de tierra en un plazo no superior a 15 días y entregó al Presidente la información sobre los objetivos para una operación aérea de 72 horas continuas (PEREA \& Murcia, 2014, p. 51).

La diferencia de tiempo es atribuible a la paciente labor de reconocimiento aéreo. En efecto la Jefatura de Inteligencia de la Fuerza Aérea había compilado, en los tres años previos, información precisa a partir del reconocimiento y vigilancia sobre la zona. Sobre esa información se logró identificar una serie de objetivos de la infraestructura que el grupo ilegal erigió allí para la producción y el tráfico de narcóticos. 
El plan: La Fuerza Aérea comprometió a sus diversas instancias de planeamiento. Al seleccionar los objetivos, por encima de todo, se evaluó que ninguno podía ubicarse en poblados o aledaños a estos. Los objetivos tampoco podían incluir alguno de los campos de concentración de los secuestrados por el grupo ilegal. Respecto a los objetivos próximos a zonas pobladas el Comando de la Fuerza Aérea decidió excluirlos. Respecto a los secuestrados, las tareas de información fueron coordinadas con las demás agencias de información de las Fuerzas Militares y de la Policía Nacional (Perea \& Murcia, 2014, p. 51, 54).

Varios de los Comandos Aéreos tuvieron una parte de la operación: CACOM 1, en Palanquero, sirvió como base de lanzamiento de las aeronaves Kfir, Mirage y T-37; desde CACOM 2, en Apiay, se lanzaron las aeronaves A-37, AC-47T, OV10 y T-27; CACOM 6, en Tres Esquinas, fue la base adelantada para la operación y recuperación de los T-27.

Por su parte, el Centro de Comando y Control de la Fuerza Aérea dispuso de su red de comunicaciones VHF. Según Perea \& Murcia (2014, p. 59), este sistema no garantizaba el contacto con las aeronaves al momento de descender sobre los objetivos para ejecutar su misión. Algo similar ocurría con la cobertura de radar, disponiendo solo del radar civil en Villavicencio para controlar el sector oriental de la zona objetivo y del radar de la base aérea de Tres Esquinas para el sector occidental.

El Comando de la Fuerza Aérea dispuso que el comando de la Base Aérea de Apiay (CACOM 2) desarrollara la operación. Allí se concentraron el personal y los equipos, incluyendo los técnicos en combustibles, comunicaciones, grupos SAR de búsqueda y rescate (RUBIANO, 2002).

Para recuperar la zona se activaron los planes 'Delta y Tora'. La denominada Operación Delta, correspondió a la Fuerza Aérea. Se usaron 31 aeronaves en total, todas con la capacidad de emplear lentes de operación nocturna (NVG). Según el tipo de misión a cumplir y las capacidades del equipo, evidenciando la versatilidad del poder aéreo, se detalla su uso en la tabla 3, así:

Tabla 3. Misiones y aeronaves en Operación Delta (2002)

\begin{tabular}{|l|l|l|}
\hline \multicolumn{1}{|c|}{ Misión } & \multicolumn{1}{|c|}{ Aeronave } & \multicolumn{1}{c|}{ Tipo de aeronave } \\
\hline \multirow{4}{*}{ Ataque e interdicción } & C-7 (Kfir) y M-5 (Mirage) & Superioridad aérea \\
\cline { 2 - 3 } & AT-27 y T-37 & Entrenamiento; acondicionadas para lanzar bombas \\
\cline { 2 - 3 } & OV-10A (Bronco) & Apoyo aéreo cercano \\
\hline \multirow{2}{*}{$\begin{array}{l}\text { Interdicción y apoyo } \\
\text { aéreo cercano }\end{array}$} & AC-47T (Fantasma) & Apoyo aéreo cercano \\
\cline { 2 - 3 } & AB-212 Rapaz & Helicópteros \\
\cline { 2 - 3 } & AH-60L Arpía II y III & \\
\hline
\end{tabular}




\begin{tabular}{|l|l|l|}
\hline $\begin{array}{l}\text { In t e l i g e n c i a, } \\
\text { vi g i l a n c i a y } \\
\text { recon oci mi ento } \\
\text { técnico }\end{array}$ & SA2-37 B y King 350 & Avión plataforma \\
\hline Asalto aéreo & Bell 212, Huey II y UH-60 & $\begin{array}{l}\text { Helicópteros para inserción de tropas y evacuar } \\
\text { heridos }\end{array}$ \\
\hline Despliegue de tropas & B-707, C-130 y CN-235 & Transporte \\
\hline
\end{tabular}

Fuente: Elaboración propia basada en Perea \& Murcia (2014, p. 53).

El combate: A las 5 del jueves 21 de febrero, la Fuerza Aérea inició la 'Operación Delta' con el bombardeo contra los objetivos previamente fijados, 85 en total, entre campamentos, talleres, bodegas de repuestos y de insumos, una pista ilegal en La Macarena; en conjunto infraestructura dedicada al narcotráfico. Para ello se utilizaron bombas de 150, 200 y 250 libras. Un balance del primer día de operaciones registró 56 salidas de aeronaves y solo un Kfir impactado por fuego enemigo, el cual pudo regresar a su base (EFE, 2002).

Después que terminó esta primera fase, la Fuerza Aérea continuó con las misiones de apoyo a las fuerzas del Ejército para la recuperación de las cabeceras municipales de la zona. A esta se le llamo 'Operación TH (Todo Honor)' (El País, 2003). Como tal, la Operación Delta se prolongó hasta el 26 de mayo de 2002, sumando "312 salidas con aeronaves de transporte e inteligencia y 233 salidas con aeronaves de combate" (FAC, 2005, p. 210); además de batir los objetivos previamente seleccionados, se brindó movilidad y apoyo logístico al Ejército.

Motivación para el combate: Recién concluyó la Operación Delta y Tora hubo un reconocimiento verbal a cada uno de los escalones que contribuyó a su éxito, notorio en cuanto participaron más de 10 tipos de aeronaves y se desarrollaron una gama amplia de misiones diferentes, todo con "cero accidentes" denotando un alto nivel de entrega (Rubiano, 2002).

Dado que Apiay se convirtió en la base de lanzamiento y recuperación de gran parte de las misiones de la Operación $\mathrm{TH}$, luego tuvo que coordinar con los diferentes mandos participantes. Entre estos se incluyeron el mismo Comando de la Fuerza Aérea, así como los respectivos comandantes del Comando Específico de la Operación TH, el del Teatro de Operaciones, el de la Fuerza de Despliegue Rápido, el de la Cuarta División, el de la Séptima Brigada, los de las Brigadas Móviles 6 a y $7^{\mathrm{a}}$ y la Policía Nacional.

\section{POLÍTICA OFENSIVA Y BOMBARDEO DE PRECISIÓN (2003-2008)}

Según SPENCER (2011) los desarrollos previos además de debilitar al grupo ilegal "crearon las condiciones para atacar a los líderes medianos y altos [así que en 
2007] mediante un bombardeo de precisión se dio el primer gran golpe dando de baja al Negro Acacio [...] luego se continuó con Martín Caballero [...] y a partir de entonces se siguió toda una secuencia de golpes importantes." (p. 107). Si bien en el pasaje citado se reconoce a 2007 como el año de los golpes exitosos, y veremos que fue gracias a la evolución táctica de la Fuerza Aérea, ${ }^{27}$ también se sugiere extender tales desarrollos desde 2002 hasta 2010, una interpretación de mayor contenido político que evidencia la dificultad de construir historia inmediata.

Vale recordar que el lapso 1998-2001 para las Fuerzas Militares fue de ofensiva permanente y una reforma que reflejó la asimilación de lecciones aprendidas. Según Leal (2010) estos factores tendieron a la inercia entre 2002-2006, dado que se redujo las acciones del grupo ilegal, pero sin propinarle algún golpe contundente (párr. 2). Por ello, afirma, la Política de Seguridad Democrática (Mindefensa, 2003) y su expresión militar, el Plan Patriota, fue tan ineficaz que llevó a su rediseño como Política de Consolidación (Mindefensa, 2007). Si a esta política, entre 2006 y 2010, con las mejoras en la inteligencia y las operaciones conjuntas, achaca los resultados destacados de 2007 y la misma 'Operación Jaque' en 2008 (LeAL, 2010, párr. 3), no explica la inercia del período previo.

Por el contrario, Spencer (2011) subraya que desde 2002 la estrategia de las Fuerzas Militares fue exitosa. En tal estrategia los mayores éxitos se lograron con las operaciones ofensivas de las Brigadas Móviles del Ejército Nacional y su articulación al Plan Patriota; en el período aquellas pasaron de ser 8 a 17 brigadas. La fase inicial del plan fue la operación 'Libertad I', iniciada en 2003, con la cual se frustró el cerco que pretendía el grupo ilegal sobre Bogotá y Cundinamarca. En la siguiente fase, se creó la Fuerza de Tarea Omega para volcar el esfuerzo sobre el sur del país; parte de este esfuerzo fue el inicio de las operaciones especiales contra los cabecillas del grupo ilegal (SPENCER, 2011, p. 86).

Un factor que coadyuvó a este éxito fue la desmovilización de los grupos de autodefensas ilegales. Con estos grupos, luego de firmarse el "Acuerdo de Santa Fe de Ralito" en julio de 2003, los diálogos llevaron a una desmovilización gradual que concluyó tres años después. El proceso también llevó a expedir la ley 975 de 2005, de "Justicia y Paz", para facilitar los procesos de paz, la reincorporación social de los miembros de los grupos armados ilegales y la reparación a las víctimas $^{28}$ (CNMH, 2014). Con menos frentes que atender, la Fuerza Pública pudo

$27 \quad$ Ya en 2001 se presentaron los avances en inteligencia aérea, como aviones con equipos de intercepción de radio y telefonía, de detección de calor; se incorporaron helicópteros artillados y blindados y se demostró una nueva técnica de bombardeo donde participaban aviones A-37, K-Fir C-7 y el AC-47T (El Espectador, 2001, Diciembre, p. 7A).

28 Entonces se creó la Comisión Nacional de Reparación y Reconciliación-CNRR-y a su interior se formó el Grupo de Memoria Histórica; este el precedente del CNMH, entre cuyos productos iniciales estaban en 2009 "Recordar y narrar el conflicto" y "Memorias en tiempo de guerra". 
concentrar más recursos en las zonas que el Plan Patriota determinó prioritarias. No obstante, algunos desmovilizados pasaron a conformar las denominadas 'Bandas criminales', generando una evolución del conflicto.

La diferencia a considerar es que, antes de estas operaciones del 2007, el esfuerzo principal solían realizarlo las Fuerzas Especiales con la Fuerza Aérea como apoyo. Ahora, con una mejor inteligencia, a la Fuerza Aérea tocaba el esfuerzo principal y luego llegaban las Fuerzas Especiales a consolidar. Priest (2013) atribuye aquellos éxitos a un programa de la CIA con apoyo del Joint Special Operations Command (JSOC), iniciado en 2003 para rescatar a tres estadounidenses secuestrados por el grupo ilegal; el programa mejoró los sistemas de inteligencia colombianos, pero no logró hallar a los rehenes ni neutralizar a los cabecillas del grupo (PRIEST, 2013, párr. 34).

Las soluciones llegaron desde la Fuerza Aérea. Allí los asesores estadounidenses propusieron usar 'bombas inteligentes'. Para lograrlo el presidente Uribe debió solicitarlas a su homólogo Bush. Luego se buscó adaptar el sistema Raytheon de los cazas estadounidenses a los A-29 Súper Tucano, sin éxito, pero funcionó en el viejo A-37 Dragonfly. Por último, el escollo legal lo resolvió un pool de abogados de la Casa Blanca, la CIA, los Departamentos de Justicia, de Defensa y de Estado: era procedente usar tales bombas contra los cabecillas de un grupo considerado una amenaza para Colombia y como narcotraficantes amenaza para EE.UU.; pero la CIA debía monitorear su uso para cumplir con la certificación de derechos humanos exigida por el Congreso de ese país (PRIEST, 2013, párr. 41-45).

No obstante, la Fuerza Aérea Colombiana debió desarrollar una nueva táctica para usar las 'bombas inteligentes'. El ataque aéreo lo inicia el A-37 que desde gran altura activa la bomba, seguido por los A-29 que volando más bajo lanzan bombas ordinarias sobre el mismo objetivo; así se buscaba ocultar el uso de la 'bomba inteligente'. Luego un AC-47, también volando bajo, con sus ametralladoras neutraliza el área inmediata en tierra alrededor del objetivo. En septiembre de 2007, por primera vez, se empleó este recurso contra alias 'Negro Acacio' y, pocas semanas después, el segundo fue alias 'Martín Caballero'. 'La muerte de los dos cabecillas provocó la deserción masiva en los destacamentos que ellos dirigían e inauguró la desintegración del grupo ilegal” (PRIEST, 2013, párr. 49).

\section{OPERACIÓN UNIVERSAL (SEP. 2007)}

Campo de combate: Entre San José del Guaviare y Barrancominas (Guainía). Barrancominas aunque es una localidad rural con menos de 1000 habitantes, era un epicentro de la producción de coca entre los departamentos de Vichada y Guainía. Aquella localidad contaba con una pista de 1.800 metros, convertida en la vértebra del narcotráfico, con un promedio de 80 vuelos mensuales. Desde 
allí una flotilla de lanchas remontaba el río Guaviare para recoger la producción de coca del grupo armado, la que negociaban con los grupos de autodefensa, los narcotraficantes del Norte del Valle o los brasileños (Semana, 2007).

El objetivo sería alias 'Negro Acacio', el cabecilla quien controlaba el narcotráfico y la adquisición ilegal de armas en el oriente del país; con aquella actividad generaba hasta un $80 \%$ de los ingresos del grupo ilegal. Al efecto mantenía contactos internacionales, como demostró la operación que en 2001 produjo la captura de alias Fernandinho, narcotraficante brasilero (Semana, 2001). Además, en 1999 negoció con el funcionario peruano Montesinos la compra de un lote de fusiles. Estaba acusado de narcotráfico, secuestro, tortura, homicidio agravado, terrorismo, extorsión, hurto, entre otros delitos, por lo que existían 23 órdenes de captura y una solicitud de extradición en su contra (Semana, 2007).

La preparación: En 2001, la Operación 'Gato negro' tuvo como objetivo principal neutralizar al cabecilla. Con ello se desarticularía el corredor de movilidad entre la Zona de distensión y los departamentos fronterizos, como desarticularía el tráfico ilegal que, desde las zonas de cultivo en los departamentos del Guaviare, Vichada y Guainía, conectaba con los países fronterizos, con Surinam y Paraguay. Previamente la Fuerza Aérea adelantó misiones de inteligencia aérea, con sus aviones plataforma Awac y Orión, registrando con rayos infrarrojo la información de apoyo para la Fuerza de Tarea Conjunta del Sur, con base en Tres Esquinas (Caquetá).

La operación se desarrolló en Barrancominas (Guainía), liderada por la Fuerza de Despliegue Rápido (FUDRA) y el Grupo Aéreo de Oriente (GAORI) de la Fuerza Aérea Colombiana. Aunque el cabecilla logró escapar, la operación condujo a la captura de alias Fernandinho, narcotraficante brasilero, así como la incautación de insumos, avionetas, vehículos venezolanos y brasileros, un cargamento de armas, entre otros materiales (VÁSQUEZ, 2001).

Desde entonces se cuentan seis intentos ${ }^{29}$ más de la Fuerza Pública para neutralizar al cabecilla (BEDOYA, 2007). En 2007, como resultado de una efectiva tarea de inteligencia, se realizó la Operación Sol Naciente. Una operación conjunta, desarrollada por la Fuerza de Tarea Omega, y coordinada con la Policía

$29 \quad$ Intentos resumibles así: desde 2001 inteligencia del Ejército volvió a infiltrar su campamento en el Meta, se planeó una operación 'Gato Negro II' pero se frustró porque llegó a la prensa; en 2003, en límites entre los departamentos de Meta y Vichada, el Ejército Nacional y la Fuerza Aérea efectuaron la operación 'Zorro', después de identificar uno de sus principales campamentos, no obstante logró huir (FAC, 2003); la operación 'Implacable' en Cumaribo (Vichada); en 2004 se ubicó su nuevo campamento, cuyo asalto tampoco produjo el resultado esperado; de nuevo se infiltró su campamento sobre el río Papunaua (Guaviare), en 2005, durante la operación Troya fue atacado el grupo de lanchas donde se desplazaba y volvió a escapar; un año después se logró infiltrar uno de sus anillos de seguridad, lo que llevó a la Operación 'Sol Naciente' cuando el cabecilla fue neutralizado. 
Nacional y el DAS, dirigida a neutralizar a alias el 'Negro Acacio'. La información de inteligencia se orientó no solo a confirmar la ubicación del campamento, también a constatar que no hubiera secuestrados allí (El País, 2007). Primero hubo un bombardeo de su ubicación, luego ingresaron las tropas para efectuar el barrido de la zona.

El combate: Con pocas horas de anticipación, en la Base Aérea de Apiay (Meta), el comandante del Escuadrón 211 recibió la orden de alistar tripulaciones para seis aviones en condiciones NVG. El liderazgo del comandante era desafiado con esa orden, cómo organizar de la mejor manera a los pilotos disponibles. Entre estos contaba con pilotos instructores y pilotos operacionales de gran experiencia, otros recién llegados de vacaciones o con poca experiencia, un grupo muy disímil. Aún más, cómo el Escuadrón podía realizar un ataque nocturno cuando nunca se había siquiera discutido sobre ello.

Hacia la medianoche, el comandante debió presentarse ante su jefe en la Base para recibir más detalles. El ataque lo realizarían dos A-37 y seis A-29B, contra un objetivo ubicado a 190 millas de Apiay, a cualquier hora desde ese momento. Muy pocos detalles para el comandante, en una operación "que por primera vez se realizaría en la Fuerza Aérea, ocho aviones con NVG, ataque simultáneo a la hora $\mathrm{H}$ contra un objetivo que no sabía que era pero que suponía era muy importante.”' (ESCOM 211, Informe Operación 'Universal', septiembre 25, 2007).

A las 01:00 horas, del sábado 01 de septiembre de 2007, se actualizó a las tripulaciones con solo un dato adicional: las coordenadas de un área general. Había que prepararse para el despegue en menos de 30 minutos, incluido un briefing de 5 minutos con los pilotos para explicar la maniobra a realizar. La hora de despegue cambió, se autorizó a las 04:00 horas. Los A-29B iniciaron su vuelo de crucero en dos escuadrillas de a tres aeronaves cada una, la segunda manteniendo contacto visual con la primera.

Desde el control de la operación se ordenó retrasar 15 minutos el ataque. Las aeronaves debían sostenerse en sobrevuelo, problema para el comandante del escuadrón cuya aeronave solo tenía un tanque de combustible. Las demás aeronaves disponían de dos tanques, es decir, disponían de una hora más para sostenerse en vuelo. Pero a continuación se anunció un nuevo retraso mientras los A-37 despegaban. También la nubosidad aumentó obligando a desplazar el escuadrón a un nuevo sitio para sobrevolar manteniendo el contacto visual.

Recibidas entonces las coordenadas específicas y estimando su llegada al objetivo el líder de los A-37 determinó la hora del ataque. Las condiciones meteorológicas empeoraban con el pasar de los minutos así que el comandante del escuadrón, buscando mejores condiciones, ordenó proceder al punto y descender; en la transición la segunda escuadrilla se separó y tampoco se veía el terreno. A escasas millas del objetivo, a las 4:33 horas, los A-37 liberaron sus 
bombas y en seguida los A-29B picaron para liberar las suyas. Sin el peso de las bombas la aeronave del comandante de escuadrón pudo regresar con combustible suficiente a su base.

Mientras regresaban, los pilotos escucharon el reporte que desde un AC47T confirmaba que el objetivo había sido impactado y la infraestructura del grupo ilegal había sido inutilizada. El bombardeo de precisión realizado por las aeronaves Súper Tucano, tuvo un margen de error de escaso un metro; ello usando bombas de 500 libras. (El Tiempo, 2007). Apenas en la base, al presentar su misión cumplida, el comandante del Escuadrón 211 escuchó de su jefe que el objetivo era alias el 'Negro Acacio'.

El mal tiempo demoró una segunda fase. Tropas de Fuerzas Especiales que volaban a bordo de cinco helicópteros Black Hawk no pudieron realizar el asalto. Apenas a las 11:10 estaban de regreso en San José del Guaviare. A las 16:45 la Fuerza Aérea realizó un nuevo ablandamiento y una hora después vino el asalto al campamento. Este fue copado en solo 25 minutos, pero la oscuridad impidió hacer un barrido de la zona obligando a las tropas a emboscarse para pasar la noche. El domingo en la mañana, a las 07:00 horas se realizó un segundo desembarco (El País, 2007; El Tiempo, 2007).

\section{Operación Aromo (OCT. 2007)}

Campo de combate: El área de la operación se encuentra entre los municipios de Zambrano, Carmen de Bolívar y San Jacinto. Esta área hace parte de la más conocida como los Montes de María, rodeada de sierras escarpadas y vegetación tupida, que corre desde el interior del país hacia la costa Caribe. El municipio de Carmen de Bolívar, el epicentro de la operación, tiene una extensión de $954 \mathrm{~km} 2$ y una población (a 2005) de 67.952 habitantes. Su geografía es quebrada, dada su ubicación dentro del sistema orográfico de los Montes de María.

Carmen de Bolívar, asentado sobre áreas indígenas descendientes del Finzenú, es fundación dieciochesca del dominio español. Su actividad económica actual está determinada por la ganadería extensiva y la producción de tabaco para exportación. Se une a través de la carretera Troncal de Occidente con la costa Caribe y el interior del país; por la Ruta del Sol con el César, por la Troncal de Oriente hacia los Santanderes y tiene acceso al Río Magdalena por carretera intermunicipal (Alcaldía de El Carmen, 2013). La operación se cumplió en la zona Aromeras Sur, a ocho kilómetros de Carmen de Bolívar.

El objetivo era neutralizar al cabecilla del grupo ilegal que delinquía entre los departamentos de Bolívar y Sucre, alias 'Martín Caballero'. Sus exacciones incluían la extorsión, el secuestro, la siembra de minas antipersonal y atentados terroristas contra la población y la Fuerza Pública. La Fiscalía General de la 
Nación lo acusó, entre otros delitos cometidos de 1992 a 2006, de los ataques a Puerto López (Antioquia), San Cayetano, San Jacinto y Córdoba (Bolívar), de varios atentados terroristas en Cartagena y en las vías del departamento de Bolívar, y del secuestro del ex ministro Araujo. En suma, era responsable de causar 420 muertos y 896 heridos civiles, así como de causar 218 muertos y 336 heridos entre miembros de la Fuerza Pública (GÉLvez et al, 2014, p. 84-88). Por lo anterior se determinó que era un objetivo de alto valor estratégico (OMAVE) a ser neutralizado.

La preparación: Entre marzo y octubre del 2007 se desarrolló la 'Campaña Alcatraz', dirigida contra el narcotráfico manejado por el grupo ilegal FARC en los departamentos de Bolívar y Sucre. En las dos primeras fases, en marzo y abril, luego de una intensa labor de inteligencia, tropas del Comando Conjunto del Caribe neutralizaron parte de las cuadrillas que delinquían en la zona (Mindefensa, 2007, Campaña, párr. 3). En la tercera fase, en octubre y llamada 'Operación Aromo', correspondió a la Fuerza Aérea neutralizar al cabecilla del grupo.

La información sobre el objetivo la obtuvo la Fuerza Conjunta de Acción Decisiva (FUCAD). La Jefatura de Operaciones Especiales Conjuntas (2007; hoy CCOES) asignó a la Armada Nacional recoger la información sobre el objetivo. Una de las fuentes de información fue el mismo ex ministro Araujo, quien permaneció secuestrado por el grupo ilegal durante seis años (del $2000 \mathrm{al}$ 2006). El cabecilla también fue objeto de interceptación de las comunicaciones, de seguimiento personal y desplazado de forma conveniente por la maniobra de fuerzas terrestres. Los anteriores factores llevaron a reducir el margen de error de su ubicación por radiogoniometría a 20 metros, en la zona rural del municipio del Carmen de Bolívar (GÉLvez et al, 2014, p. 90). Confirmada su ubicación se ordenó aplicar el poder aéreo contra el objetivo.

El 23 de octubre, hacia las 20:00 horas, de parte de la Jefatura de Operaciones Especiales se recibió en CACOM 3 (Malambo, Atlántico) la información para la operación. Veinte minutos después se hizo el planeamiento con el comandante del grupo de combate aéreo. De modo que a las 21:00 horas se dispuso armar las aeronaves y llegado ese material, entre las 23:00 horas y las 05:00 del día siguiente se adelantó la configuración de las mismas. Después de actualizar alguna información, apenas a las 16:30 se ordenó iniciar las misiones asignadas. En ese momento, con un briefing de solo 5 minutos los pilotos fueron avisados de su misión; una medida para garantizar la reserva sobre el objetivo a alcanzar.

Las tácticas: El 24 de octubre de 2007, a las 17:30 horas, despegaron dos aviones A-29B desde la base de CACOM 3. Cinco minutos después les siguieron cinco aviones A-37B; debían realizar una misión de ataque estratégico ${ }^{30}$. A las

30 En los medios de prensa se hace un manejo equívoco sobre los conceptos de ataque y bombardeo. La misión u operación de "ataque estratégico", aunque acción ofensiva desde el aire contra objetivos 
18:10 horas, se les sumó un avión SA2-37B para apoyarlos con la misión de servicios para el combate y operar como controlador aéreo. Para evitar que el grupo ilegal rastreara la operación, en las comunicaciones aeronáuticas se procedió como si fueran aeronaves comerciales.

Durante la operación los pilotos también mantuvieron silencio de radio, al tiempo que debió preverse evitar la alteración del tránsito aéreo del sector. Igual se previó no afectar a las tropas terrestres, listas a corta distancia para ocupar el objetivo. Para esto el SA2-37B se sostuvo en sobrevuelo reconociendo con sensor infrarrojo para coordinar el asalto aéreo y las tropas de superficie; vale subrayar que se trataba de una operación nocturna.

El mismo día, a las 18:35 horas, despegaron con dirección al objetivo un helicóptero AH-60L ('Arpía') y en seguida un UH-60, con equipo de visión nocturna (NVG). El primero perteneciente al CACOM 5, con base en Rionegro (Antioquia), el segundo era de la Aviación del Ejército. El despegue se hizo desde la pista de Zambrano (Bolívar), sede de la Brigada de Infantería de Marina 16 (BRIM-16). El helicóptero AH-60L debía cumplir dos misiones: de apoyo aéreo cercano y de defensa aérea. Este Arpía no podía disparar a más de $500 \mathrm{~m}$. por fuera del área objetivo, para no afectar a las propias tropas que hacían parte de los cierres y observatorios en tierra. También debía designar dos zonas de desembarco, una $200 \mathrm{~m}$. hacia el sur del objetivo y otra a $200 \mathrm{~m}$. hacia el norte del mismo (GÉLVEZ et al, 2014, p. 94).

El combate: A las 17:52 horas, dos A-37B lanzaron bombas de precisión sobre el objetivo; en seguida y hasta las 17:54, otros tres A-37B y los dos A-29 lanzaron bombas ordinarias alrededor de donde se encontraban los miembros del grupo que protegían al cabecilla. "En un minuto y 47 segundos los aviones entregaron armas en una superficie de una hectárea lo cual demuestra el alto grado de precisión y coordinación de los pilotos de combate de la Fuerza Aérea Colombiana." (GÉLVEZ et al, 2014, p. 93). En total se lanzaron 32 bombas, cuya precisión fue del 100\% sobre el objetivo.

Pasado el bombardeo, a las 18:45 horas, arribó al objetivo el helicóptero AH60L, escogió la zona de desembarco sur y lo preparó con cohetes y munición .50, como en seguida designó la zona norte al UH-60 e iniciaron el estacionario para la inserción por rappel de los comandos. En la zona sur desembarcaron 18 comandos del BACOA ${ }^{31}$ para consolidar el objetivo; en la zona norte otros 17 para impedir la

militares en tierra y agua, procura neutralizar los centros de gravedad del contrario (FAC, 2013, Manual, p. 87). El "bombardeo estratégico" se remite al paradigma doctrinal de las guerras mundiales cuando se bombardeó masiva e indiscriminadamente las retaguardias enemigas; pese a su nula efectividad, solo medio siglo después se adoptó paulatinamente el "bombardeo de precisión" (HAULMAN, 2014. p. 156).

31 Batallón de Comandos, creado en 2002 durante el gobierno Pastrana, para atacar objetivos de alto valor y lanzar asaltos aéreos sobre el campo enemigo; primero dependió del Comando de Operaciones Especiales del Ejército (RAMSEY, 2009, p. 98; Moyar et al., 2014. p. 30). 
fuga de los efectivos del grupo ilegal. Mientras el AH-60L se quedó en apoyo de las tropas, el UH-60 retornó a Zambrano por el otro destacamento de comandos.

No obstante, al bombardeo los helicópteros fueron recibidos con disparos de los miembros del grupo ilegal, incluso de ametralladora M-60. Una vez desembarcados los comandos de la segunda zona tuvieron que pedir apoyo de fuego, "comenzando así una combinación de armas tanto de la tropa como del Arpía con cohetes, munición calibre .50, ametralladoras, lanza granadas, fusilería y bengalas durante varios minutos" (GÉLVEZ et al, 2014, p. 104). Luego de solicitar alto al fuego iniciaron el registro y encontraron al cabecilla muerto, pese a que su gente de huida intentó llevarse el cuerpo; otros 18 efectivos del grupo también fueron neutralizados por la Fuerza Pública.

Motivación para combate: “'Alcatraz' fue una exitosa operación conjunta de las Fuerzas Militares de Colombia donde la Armada Nacional aportó la inteligencia, la Fuerza Aérea realizó el ataque estratégico y el Ejército Nacional consolidó la operación" (GÉLVEZ et al, 2014, p. 99). La Armada Nacional fue la fuerza que durante más tiempo enfrentó a la fracción del grupo ilegal en los Montes de María, perdiendo 242 efectivos entre oficiales, suboficiales e infantes de marina. También la Policía Nacional perdió unos 20 efectivos a manos del grupo en esa región del país (ARC, 2007, párr. 8).

\section{FUERZA AÉREA, LA DECISIVA Y UNIDADES CONJUNTAS (2009-2015)}

En alguna perspectiva foránea el relativo éxito de Colombia, contra el narcotráfico y los grupos armados ilegales, es atribuible al desarrollo a largo plazo de capital humano en la Fuerza Pública. Esta tendencia la complementaron los asesores estadounidenses con la promoción de oficiales y funcionarios colombianos a posiciones de liderazgo (Moyar et al, 2014, p. ix). En otra perspectiva el desarrollo de una capacidad nacional a largo plazo es evidente por cuanto la Política de Seguridad Democrática (Mindefensa, 2003) fue continuación de la "Iniciativa para la paz" (1988) del gobierno Barco y de la "Estrategia contra la violencia" (1991) del gobierno Gaviria; estas dos, políticas con una visión político-estratégica del conflicto (Santos, J., 2007, p. 354). El aparente bache entre ellas lo explica el diferendo con EE.UU. durante el período Samper y el giro de énfasis que propició el gobierno Pastrana.

Después de las exitosas operaciones de 2007 y 2008, parecía que el conflicto se había estancado. Los críticos del primer gobierno Santos lo atribuyeron a la presión de este sobre la Fuerza Pública para neutralizar cabecillas del grupo ilegal (MoyAR et al., 2014, p. 39); a su vez, este grupo mantenía la capacidad de daño y un número importante de efectivos. La presión generaba mayor competencia entre los 
componentes de la Fuerza Pública, como sus agencias de inteligencia eran reacias a compartir información más que todo la pertinente para las fuerzas de élite.

Así cada instancia tendía a responder solo por los objetivos asignados por el gobierno. El Comando Conjunto de Operaciones Especiales-CCOES, creado en 2009 y dependencia directa del Ministro de Defensa, debía neutralizar a la cúpula del grupo ilegal. La Brigada de Fuerzas Especiales, que dependía exclusivamente del Ejército Nacional, debía neutralizar a los cabecillas de nivel medio. Las unidades elite, dependientes del Ejército, la Armada y la Policía, debían responder por otros objetivos; pero si alguna unidad regular o de inteligencia tenía información conducente a neutralizar algún cabecilla podía proceder.

La misma tendencia de despliegue de fuerzas élite implicó más tiempo peinando zonas rurales, algo que muchos miembros del Ejército preferían al disminuir la posibilidad de daños colaterales en áreas pobladas. No obstante, gran parte de la Fuerza Pública estaba dispersa en tareas de protección de la infraestructura nacional. Por ende, el grupo ilegal pudo recobrar su influencia en estas aéreas; lo que fue el principal logro del gobierno Uribe, la seguridad de la población, pareció afectarse con aquella tendencia (MoYAR et al., 2014, p. 41-42).

La Fuerza Aérea, excepto por el componente aéreo incluido en el CCOES, debía garantizar para todos el dominio del espacio aéreo. No obstante, los análisis estadounidenses, de la National Defense University (Spencer, 2011, p. 90) y la Joint Special Operations University (MoYAR et al., 2014, p. 36), coinciden en el papel decisivo de la Fuerza Aérea: antes, las fuerzas terrestres realizaron el esfuerzo principal contra objetivos de alto valor; ahora, con el bombardeo de precisión la Fuerza Aérea realizó el esfuerzo principal, luego las fuerzas élite aseguraban la zona y las demás fuerzas terrestres apoyaban tal esfuerzo.

Ejemplo de ello podría ser la Operación Sodoma, en 2010, que implicó la participación del CCOES, las Fuerzas Especiales y la Fuerza Aérea. Una operación decisiva por cuanto neutralizó a alias 'Jojoy', miembro de la cúpula del grupo ilegal y el cabecilla más agresivo desde 1996. "Su muerte definitivamente marcó el fin de una era" (SPENCER, 2011, p. 109).

\section{OPERACIÓN SODOMA (SEP. 2010)}

Campo de combate: El municipio de La Uribe colinda con la Serranía de La Macarena. El campamento del cabecilla estaba ubicado a $26 \mathrm{~km}$. al suroeste del municipio, tenía una extensión de $300 \mathrm{~m} 2$, con una construcción en concreto y túneles de escape. Rodeado a su vez por otros 12 campamentos, que albergaban en conjunto unos 400 miembros del grupo ilegal (BEDOYA, 2010). El complejo contaba con bodegas, áreas de reunión, enfermería, sastrería y maquinaria fabril; protegido con minas y ametralladoras antiaéreas .50 y M-60. La seguridad del 
complejo se escalonaba en tres anillos, el primero era el inmediato al cabecilla; el segundo, a 100 metros, y un tercero a 500 metros. Conformaba así un perímetro con un efectivo ubicado cada metro en promedio.

Considerando que ese destacamento del grupo ilegal que delinquía en los departamentos de la Orinoquia intensificó sus acciones, para su debilitamiento el objetivo era neutralizar al cabecilla alias 'Mono Jojoy'. El prontuario de este sumaba más de 105 delitos, entre ellos lesiones personales, homicidio agravado, secuestro extorsivo, terrorismo, tráfico de armas y narcotráfico; por los que acumulaba más de 8 órdenes de captura y había sido condenado a más de 150 años de prisión (GÉLVEZ et al, 2014, p. 109-111). Fue responsable de los ataques a la base de Patascoy (Nariño, 1998) y de La Carpa (Guaviare), de los secuestros de la candidata política Betancur (2002), del ex gobernador A. Jara, el asesinato de la ex ministra C. Araujo y el plagio de un niño, hijo de la política Clara Rojas. En suma, era responsable de causar cientos de muertos y heridos civiles, como entre miembros de la Fuerza Pública (GÉLVEz et al, 2014). Por lo anterior se determinó que era un objetivo de alto valor estratégico (OMAVE) a ser neutralizado.

La preparación: Definido dicho cabecilla como uno de los objetivos, mientras una de las 'burbujas' ${ }^{32}$ del CCOES actualizaba permanentemente la información, el Comando dirigía las acciones sobre el terreno para reducir paulatinamente el área de ubicación del objetivo (GÉLvez et al, 2014, p. 114-115). Como esfuerzo conjunto y coordinado, en este caso, la 'burbuja' estuvo a cargo de la Armada Nacional, pero recibió los insumos de inteligencia técnica y táctica del Ejército Nacional; de inteligencia de imágenes aéreas y satelitales de la Fuerza Aérea; y de inteligencia humana de la Policía Nacional (GÉLvez et al, 2014, p. 115).

Algunos intentos previos para neutralizar al objetivo fallaron porque los enlaces al interior de la Fuerza Pública necesitaban mejorarse o porque los anillos de seguridad del cabecilla fueron efectivos para impedir el acceso. En este orden, si con las tropas de superficie se determinó un área general de 10 $\mathrm{km} 2$; con la inteligencia policial la ubicación del objetivo se precisó dentro de $1 \mathrm{~km} 2$. Precisión esta que permitía el uso adecuado del poder aéreo. De modo que al planear la operación el esfuerzo principal recayó sobre la Fuerza Aérea.

Una premisa permanente de la operación fue la reserva de la información. Pese al flujo de información desde las diferentes agencias del Estado, solo unos pocos individuos en el CCOES, en la 'burbuja', en la planeación y en su preparación conocieron los detalles finales para neutralizar el objetivo. A mediados de septiembre de 2010 cuando, de nuevo, se confirmó su ubicación hubo una febril actividad del personal de inteligencia de la Fuerza Pública para consolidar la

32 Burbuja es una denominación no oficial que define al equipo encargado de reunir la información sobre un objetivo específico (GÉLVEZ et al, 2014. p. 114-115). 
información. Desde el viernes 17 de septiembre en la base militar de Larandia el alto mando intensificó los preparativos. En cinco días se ultimaron los detalles de la operación (El Diario, 2010; Semana, 2010b).

El área de la operación presentó dificultades adicionales, entre ellas: la abundante pluviosidad que afecta la movilidad en tierra; la permanente nubosidad que entorpeció el reconocimiento aéreo y la vegetación espesa que dificultó identificar la infraestructura del área. Aquí la Fuerza Aérea aportó otro de sus atributos: los analistas de imágenes apoyaron el lograr el mayor nivel de precisión en la información, determinando los rumbos de entrada, las zonas de desembarco, entre otros detalles que garantizaron el cumplimiento de las misiones aéreas (GÉLVEZ et al, 2014, p. 118).

Una de las misiones era de ataque estratégico, el bombardeo simultáneo sobre la ubicación del cabecilla y sobre la disposición de armas antiaéreas del grupo ilegal. Esta última también con el fin de garantizar la superioridad aérea en el área de la operación. Superioridad que a su vez aseguraba la vida de las tripulaciones como de las Fuerzas Especiales al desembarcar. No obstante, la principal limitación era el tiempo. Luego que la inteligencia policial ubicó el objetivo en un radio de $1 \mathrm{~km} 2$, debía procederse dentro de 24 horas antes que el cabecilla se moviera a otra ubicación.

Las tácticas: Como responsable del esfuerzo principal de la operación, la Fuerza Aérea comprometió unos 30 aviones de combate, inteligencia, transporte y ambulancia; más helicópteros artillados, de transporte y de rescate. Así como el apoyo del sistema logístico y su Centro de Comando, Control y Comunicaciones. No obstante, la "fase final del planeamiento desafió las capacidades distintivas, al proponer a las tripulaciones una hora de ataque a escasos 120 minutos del inicio del briefing" (RUEDA, 2011). El desarrollo de la operación correspondió a la Fuerza de Tarea Conjunta Omega; Aviación del Ejército empleó 34 helicópteros, para transportar no menos de 700 efectivos.

El martes 21 de septiembre, en la mañana, comenzó el avance de las tropas de superficie. Pero solo en la madrugada del miércoles 22 se inició el bombardeo. Para este se usaron 'bombas inteligentes', cuya capacidad de acertar en la selva es casi milimétrica ${ }^{33}$. Cumplido el bombardeo, se realizaría el desembarco de 400 comandos con apoyo cercano de los helicópteros Arpía. También apoyados por un AC-47T, que adicionalmente haría reconocimiento de las vías de acceso al campamento por donde podrían huir los miembros del grupo ilegal. La tarea de los primeros comandos en desembarcar era copar a los guardias de los cerros aledaños al campamento, neutralizando su acción sobre las aeronaves de bombardeo (Semana, 2010a).

33 Entre ellas: una bomba de gravedad de 500 lbs., acondicionada con un GPS para guiarla por láser (Raytheon's Enhanced Paveway II) y que puede lanzarse desde una aeronave A-37 Dragonfly (PRIEST, 2013). 
En suma, siempre habría una aeronave con medios técnicos de inteligencia para ofrecer información de combate; y siempre habría una aeronave con armamento para apoyo cercano de las tropas. Estas misiones ocuparon más de 24 horas, pero se hizo el relevo oportuno de las tripulaciones (GÉLvEZ et al, 2014, p. 120). Todas las aeronaves dispusieron de equipos de visión nocturna.

El combate: El miércoles 22 de septiembre de 2010, a las 01:00 horas se realizó el bombardeo sobre el primer objetivo, la ubicación del cabecilla. Una hora después de lo planeado, cuando se garantizó su ubicación. Las aeronaves que debían atacar el segundo objetivo, las armas antiaéreas, no despegaron a la espera de que mejoraran las condiciones climáticas.

Media hora después llegó el primer grupo de comandos, que una vez desembarcaron debieron recibir apoyo de los helicópteros artillados y del AC-47T ante la reacción de los miembros del grupo ilegal. No obstante, se logró consolidar el área de desembarco, los combates se intensificaron alrededor del primer objetivo (GÉLVEZ et al, 2014, p. 121). Ante esta reacción, hacia mediodía del miércoles fue necesario realizar un segundo bombardeo y desembarcar más tropas.

Otras aeronaves procedieron a neutralizar los puestos de guardia del grupo ilegal, en cada uno de los anillos de seguridad que rodeaban al objetivo. Después de 27 horas de combate los comandos pudieran avanzar hacia tal objetivo y confirmar que el cabecilla había sido neutralizado (Semana, 2010a). En la operación resultaron muertos más de 20 miembros del grupo ilegal. Entre los soldados 16 fueron heridos en combate. También murió uno de los perros antiexplosivos del Ejército.

\section{OPERACIÓN OdiseO (NOv. 2011)}

Campo de combate: Suárez (Cauca) fue elevado a municipio hace poco más de un cuarto de siglo. Por su ubicación en las estribaciones de la Cordillera Occidental y aledaño al río Cauca en sus inmediaciones se levantó el embalse e hidroeléctrica de Salvajina. De vieja estación de ferrocarril pasó a tener una carretera rudimentaria, que le comunica con los municipios vecinos de Buenos Aires, al norte, y de Morales, al sur; aunque el embalse aglutina un sistema de comunicación fluvial más denso. Su poblamiento es atribuido a la riqueza aurífera y otros minerales, que junto con las obras del embalse atrajo la inmigración (Alcaldía de Suárez, 2012).

Lejos del casco urbano de Suárez, por camino de herradura y ascendiendo a 2.000 metros de altura en la cordillera, se encontraba el campamento de alias 'Alfonso Cano'. En una zona al norte del departamento del Cauca que sirve de corredor con los departamentos del Tolima y Huila, así como da paso hacia el Pacífico (Noguera, 2011, Noviembre). 
Alias 'Cano' fue cabecilla del Bloque Occidental del grupo ilegal, cuya área de acción era el Macizo Colombiano con injerencia en los departamentos del Tolima, Huila, Valle, Cauca, Nariño y Putumayo. Desde mayo de 2008 asumió como máximo cabecilla del grupo ilegal, por lo cual "era el principal Objetivo Militar de Alto Valor Estratégico (OMAVE) asignado por el Gobierno al Ejército Nacional" (Gamba et al., 2012, p. 16). Entre otros delitos de los que fue responsable figuran la muerte de seis niños de la policía cívica en Algeciras (Huila, 1990); muerte de la familia Turbay en Caquetá (2000); secuestro de 9 civiles en Neiva (2001); secuestro y muerte de doce diputados del Valle del Cauca (2007); atentados con bomba en Toribío (Cauca, 2001) y contra el Club El Nogal en Bogotá (2003); ataques con armas no convencionales contra las poblaciones de Florida, El Mango, Paujil, Miranda, Jambaló; reclutamiento forzado de menores.

Por lo anterior, en su contra existían más de 94 órdenes de captura por delitos como terrorismo, homicidio, secuestro y lesiones personales, entre otros. Ordenó los ataques contra las bases militares de Las Delicias (Putumayo, 1996) y El Billar (Caquetá, 1998), así como contra la base de la Armada Nacional en el cerro Tokio (Valle). También de los ataques al municipio de Planadas (1994), a unidades del Batallón Caicedo (Purificación, 1994), el secuestro de policías en San Antonio (Tolima, 1994), emboscada a unidad policial en Ortega (Tolima, 1994), la muerte de cuatro policías en Dolores (Tolima, 1996). Fue condenado por la toma de Mitú en 1998, por el ataque a Puerto Lleras (Meta, 1999), por la masacre en Tierra Alta (...), por la muerte de un niño en Vistahermosa (Meta), por el ataque a unidades de la Fiscalía en San José de Apartadó (Antioquia, 2002) (GÉLVEZ Et al., 2014, pp. 129-132; Vanguardia Liberal, 2011).

La preparación: Desde 2009 la Central de Inteligencia del Ejército intensificó la recogida de información sobre el cabecilla. Unidades de Fuerzas Especiales hicieron reconocimiento de la zona donde se ubicaba aquel, incluso franqueando sus anillos de seguridad. El CCOES planeó una operación, realizada en mayo de 2010 sin éxito. El ciclo se repitió, lanzando una segunda operación en agosto de ese año. Y una vez más se repitió así, en junio 2011, se lanzó una operación con igual resultado fallido (GÉLVEZ et al., 2014, p. 136, 139; CASTRILLÓN, 2011).

La recogida de información se efectuó a través de medios de inteligencia humana (desmovilizados, capturados, infiltrados y análisis documental); inteligencia técnica (monitoreo de comunicaciones e interceptación de celulares). Esta tarea con acompañamiento permanentemente de unidades de la Fiscalía General de la Nación; e inteligencia de combate, cumplida por las tropas de la Quinta División en el área de operaciones.

El reconocimiento lo hicieron miembros de las Fuerzas Especiales, traspasando los anillos de seguridad del objetivo en cada ocasión previa a las operaciones. En total lograron infiltrarse en ocho ocasiones obteniendo detalles sobre la ubicación 
de campamentos, la identificación de los individuos allí y las evidencias que confirmaban la presencia del cabecilla (alimentación, rutina diaria, armamento, etc.). Las sucesivas operaciones, desde mayo de 2010 hasta julio de 2011, presionaron a que el cabecilla se fuera desplazando progresivamente hacia el sur. Desde el Cañón de Las Hermosas (municipio de Chaparral, Tolima), pasando por Planadas (Tolima) y Santa Ana (Huila), hasta llegar a Belalcázar (Cauca) (Las Fuerzas, 2011, p. 3).

Aparte de las operaciones directas contra el cabecilla, los anillos de seguridad fueron sucesivamente debilitados, desde marzo de 2010, por acción de las tropas de la Quinta División del Ejército y de la Fuerza de Tarea del Sur del Tolima. Subalternos o miembros de tales anillos fueron muertos o capturados en desarrollo de acciones en San Miguel, Planadas, Natagaima y Río Blanco (Tolima), en Aipe (Huila) y en Páez (Cauca). Además de la información recopilada en cada ocasión, el debilitamiento de su entorno de seguridad condujo a que, en julio de 2011, el objetivo se desplazara hacia el Cauca buscando más protección (Gamba et al., 2012, pp. 60-62).

Inteligencia de la Policía confirmó que efectivos del grupo ilegal, en el municipio de Suárez, tenían la tarea de proteger al cabecilla (BEDOYA, 2012). De hecho, la Policía vigilaba a otro cabecilla, quien lideraba el Bloque Occidental del grupo y quien luego murió al lado del máximo cabecilla en la Operación Odiseo (Reportero 24, 2011). En suma, se trató de una operación conjunta y coordinada. Conjunta entre el Ejército Nacional y la Fuerza Aérea; coordinada entre las tropas del Ejército Nacional, la Policía Nacional y el Cuerpo Técnico de Investigación de la Fiscalía General.

Los Estados Mayores de las Fuerzas Especiales del Comando General prepararon la operación durante los 19 días antes de su ejecución. Se escogieron cuatro bases de lanzamiento: Popayán, Cali, Tuluá y Palmira. Más de 30 helicópteros de la Aviación del Ejército y soldados de las Fuerzas Especiales se concentraron en la plataforma de lanzamiento para realizar la operación. Para el apoyo aéreo cercano más de 15 aeronaves de transporte, reconocimiento, combate, inteligencia, tácticas y aeronaves "medicalizadas" ${ }^{34}$ fueron empleadas durante la operación (Las Fuerzas, 2011, p. 3).

Las tropas de las Fuerzas Especiales del Ejército Nacional que inicialmente estaban concentradas en Tolemaida, comenzaron su despliegue una semana antes. Estas tropas hacían parte de la Brigada de Fuerzas Especiales, unidad que combatió al grupo ilegal en los Montes de María y algunos de cuyos efectivos participaron en la Operación Sodoma. El 04 de noviembre, a las 01:00 horas, las tropas comenzaron su embarque en aeronaves C-130. A las 5:30 estaban a bordo de los Black Hawk, pero el clima obligó a esperar.

34 El término 'medicalizada' es anglicismo; la palabra más adecuada sería, según la RAE, "medicinal. adj. Perteneciente o relativo a la medicina" (2001). 
La Fuerza Aérea comprometió en la operación 3 Aviones A-37; 5 Aviones A-29 Súper Tucano; 4 Helicópteros Arpía; 3 Aviones C-130, 2 aviones AC-47T y un helicóptero de rescate; para un total de 18 aeronaves (Infobae, 2011). Parte de la Aviación del Ejército se concentró en Palmira (Valle) listos para la acción, 30 helicópteros Black Hawk; algunas de sus tripulaciones estuvieron un año antes en la Operación Sodoma.

El combate: Odiseo fue una operación diurna, realizada a horas no comunes para diferenciarla de otras operaciones. La operación se lanzó el viernes 04 de noviembre de 2011 en el área del municipio de Suárez (Cauca). Hacia las 08:30 horas aeronaves A-37 y A-29 Súper Tucano, de la Fuerza Aérea, realizaron un bombardeo alrededor de la ubicación del cabecilla, su alojamiento y el de sus lugartenientes. En seguida 18 helicópteros Black Hawk de la Aviación del Ejército desembarcaron las tropas de Fuerzas Especiales usando la técnica de rappel, mientras recibían apoyo de helicópteros Arpía de la Fuerza Aérea. De la primera oleada de helicópteros siete fueron impactados por los miembros del grupo que disparaban una ametralladora M-60 y una .50 (Bolaños, 2011).

Una aeronave de la Fuerza Aérea desde 5.000 pies de altura realizó el comando y control de todas las fases de la operación. A las 13:00 ya habían desembarcado 969 tropas en los diferentes sitios para bloquear las rutas de escape. La resistencia del grupo alrededor de la ubicación del cabecilla hizo necesario un segundo bombardeo. Los combates se sostuvieron durante el transcurso del día. Copada la ubicación del cabecilla se procedió a identificar los muertos y recoger evidencias por agentes del Cuerpo Técnico de la Fiscalía; del cabecilla solo estaban sus elementos personales.

Al caer la noche se hizo otra inspección del alojamiento y sus alrededores. Justo a las 21:19 horas, en uno de los puntos de bloqueo, un efectivo de Fuerzas Especiales detectó con sus lentes de visión nocturna el intento de huida del que resultó ser el cabecilla (Gamba et al., 2012, p. 64-66; Gélvez et al., 2014, p. 137). La inmediata preocupación fue evitar que sus compinches recuperaran el cadáver, por lo que el AC-47T y los Tucano mantuvieron su apoyo a las tropas de superficie.

Motivación para combate: Una operación para dar con el cabecilla, en febrero de 2008, al sur del Tolima se saldó con 40 bajas del Ejército, entre heridos y muertos. Luego en persecución del mismo, por las estribaciones del río Ata, 42 militares cayeron por efecto de las minas anti-personal sembradas por el grupo ilegal. En abril de 2010, mientras perseguían al cabecilla, dos helicópteros colisionaron causando la muerte 7 militares.

"Cuando la Fuerza Pública logra el objetivo, dar de baja a Cano y consolidar la estrategia el sur del Cauca, se nota un cambio en la guerra, quedando desestabilizado el secretariado y todos los atentados terroristas a gran escala. Las FARC sufren una pérdida que aún no se han podido recuperar, pues su reemplazo 
alias 'Timochencho' no está en el país y han perdido la iniciativa. Tal es así, que las FARC posterior a la pérdida de Cano no han podido consolidar una guerra de guerrillas, ha limitado sus operaciones, y ha perdido influencia en territorios, no tienen un líder representativo. Esto ha sido positivo para el ambiente político, que en medida de sus pérdidas, ofreció unos diálogos de paz, que fueron acogidos inmediatamente por el grupo insurgente." (GÉLVEZ et al., 2014, p. 137)

Un balance, en noviembre de 2011, luego de la neutralización del cabecilla destacó cuatro factores que permitieron al estado colombiano debilitar al grupo ilegal (El Tiempo, 2011, noviembre). Primero una política de estado que, según varios autores citados más arriba, puede remontarse al gobierno Barco (1988) pero a la que los gobiernos Pastrana y Uribe dieron un giro decisivo. Política que incluiría mínimo tres aspectos: modernización de la Fuerza Pública, acción integral y consolidar capital humano. El otro factor fue la ventaja aérea que, desde 1998 con la recuperación de Mitú, frustró el plan del grupo para pasar a una guerra de movimientos y debilitó su dirigencia.

La Fuerza Aérea también fue clave en un tercer factor, la inteligencia. En efecto las virtudes de la inteligencia aérea llevaron a recuperar en mínimo tiempo la zona de distensión y desde 2007 se complementaron con su modernización en otras Fuerzas para ubicar a los cabecillas del grupo ilegal. Un cuarto factor ha sido la progresiva adopción del enfoque de operaciones conjuntas que inició también en 1998 con la 'Fuerza de Tarea Conjunta'.

\section{A MODO DE CONCLUSIÓN: BALANCE DE OPERACIONES DECISIVAS}

En marzo de 2015 el gobierno Santos anunció la suspensión de los bombardeos contra el grupo ilegal. El gobierno adujo que era en reciprocidad luego que este anunció un cese temporal de acciones violentas. Pero el temor a los bombardeos lo admitió ya en 2012 uno de los cabecillas del grupo (Verdad Abierta, 2015, párr. 2). Así que estamos ante un efecto de lo decisivo que resultó el bombardeo de precisión realizado por la Fuerza Aérea Colombiana. En particular una consecuencia de la evolución de las capacidades de la Fuerza Aérea, incluyendo desde la adopción de sistemas de visión nocturna y de los aviones Súper Tucano, hasta las bombas guiadas por láser.

El bombardeo de precisión permitió, en 2002, recuperar la zona de distensión en muy corto tiempo. Como permitió, desde 2007, debilitar al grupo ilegal en sucesivas operaciones sobre las que hay algún consenso cuáles tuvieron mayor impacto en el conflicto (véase tabla 4). Una versión de prensa incluye 12 operaciones de bombardeo (Verdad Abierta, 2015); otra alude al "Top 5" de los bombardeos, en orden de importancia, en las operaciones 'Fénix', 'Sodoma', 
'Odiseo', 'Sol naciente’ y en 1990 la operación 'Colombia' (Vanguardia Liberal, 2015). Otra más, resalta la coordinación Fuerza Aérea y Policía Nacional que entre 2008 y 2009 neutralizó 12 cabecillas del grupo. Más reciente, en 2015, sendos bombardeos contra fracciones del grupo en Cauca y Chocó neutralizaron 54 de sus efectivos, entre estos dos cabecillas que fueron 'negociadores' en La Habana; hecho por el cual el grupo intentó el reinicio de sus acciones violentas.

Como se ha insistido aquí, un acierto que hizo decisivas estas operaciones fue usar el bombardeo de precisión contra los cabecillas del grupo armado ilegal. Tratándose de cabecillas de fracción (llámense bloques, frentes o columnas) su neutralización redundó, en varias ocasiones, en la desarticulación de las respectivas fracciones. Según el Ministerio de Defensa (2015, Junio, p. 1), entre 2010 y 2015, se neutralizaron 60 cabecillas de diferente nivel y otros 17.261 miembros (entre muertos, capturados y desmovilizados) del grupo. Otro balance especifica que fue entre 2007 y 2011 cuando se neutralizaron los máximos cabecillas $^{35}$. Lo cierto es que, desde entonces, el grupo decidió limitarse a usar tácticas de guerrilla y multiplicar los actos terroristas para mantener su vigencia como tal (Mindefensa, 2015, p. 18 y 2012, p. 13). Por lo mismo, no es casual que el porcentaje de municipios atacados por los grupos ilegales se incrementó en 2012 y 2013 (8\% de 1.102 municipios; Mindefensa, 2015, Junio, p. 4).

Tabla 4. Operaciones decisivas con bombardeo de precisión 2007-2015

\begin{tabular}{|c|c|c|c|c|c|}
\hline Año & Mes & Operación / Tipo & Área & Cabecilla & Fracción \\
\hline \multirow[t]{2}{*}{2007} & Septiembre & Sol naciente / Conjunta & Guainía & 'Negro Acacio' & 16 \\
\hline & Octubre & Aromo & Bolívar & 'Martín Caballero' & 37, Caribe \\
\hline \multirow[t]{2}{*}{2008} & Marzo & Fénix & Putumayo & 'Raúl Reyes' & Cúpula \\
\hline & Julio & Gibraltar/Conjunta & Cauca & 'Dago' & 6 \\
\hline 2009 & Diciembre & $\begin{array}{l}\text { Oriente/Coordinada FAC- } \\
\text { Ponal }\end{array}$ & Antioquia & 'Danilo' & 9 \\
\hline \multirow[t]{3}{*}{2010} & Marzo & $\begin{array}{l}\text { Baltazar / Coordinada } \\
\text { FAC-Ponal }\end{array}$ & Tolima & 'Enrique Zúñiga' & 50 \\
\hline & Septiembre & $\begin{array}{l}\text { Fortaleza II / Coordinada } \\
\text { FAC-Ponal }\end{array}$ & Putumayo & 'Domingo Biojó' & 48 \\
\hline & Septiembre & Sodoma / Conjunta & Meta & 'Mono Jojoy' & Oriental \\
\hline 2011 & Noviembre & Odiseo/Conjunta & Cauca & 'Alfonso Cano' & Cúpula \\
\hline 2012 & Marzo & Armagedón/Conjunta & Meta & $\begin{array}{l}6 \text { cabecillas: 'Arcesio } \\
\text { Niño', 'Gildardo'... }\end{array}$ & 27 \\
\hline
\end{tabular}

35 Dos balances diferentes provienen de la misma instancia de Mindefensa y de la misma fecha (2015, junio): uno es el de la gestión del Ministro de Defensa saliente; el segundo va más atrás en el tiempo para sugerir las líneas de acción del Ministro entrante. En perspectiva de política estatal, la diferencia reflejaría el abandono definitivo de la tendencia instaurada desde 2002. 


\begin{tabular}{|l|l|l|l|l|c|}
\hline 2013 & Enero & Elipsis / Conjunta & Córdoba & 'Jacobo Arango' & 5 \\
\cline { 2 - 6 } & Agosto & $\begin{array}{l}\text { Darién / Coordina da } \\
\text { FAC-Ponal }\end{array}$ & Chocó & 'Silver' & 57 \\
\hline $\mathbf{2 0 1 4}$ & Enero & Conjunta & Arauca & 'Franklin Morales' & 10 \\
\hline $\mathbf{2 0 1 5}$ & Mayo & Conjunta & Cauca & 'Jairo Martínez' & 29 \\
\cline { 2 - 6 } & Mayo & Conjunta & Chocó & $\begin{array}{l}\text { 'Román Ruiz' y } \\
\text { 'Emiro Chaqueto' }\end{array}$ & Noroccidente, 18 \\
\hline
\end{tabular}

Fuente: Elaboración propia basada en Gamba et al. (2012); Gélvez et al. (2014); Mindefensa (2011, p. 32); Semana (2009, Diciembre 6); Vanguardia Liberal (2015, Agosto 4); Verdad Abierta (2015).

El mismo gobierno al anunciar en 2012 el comienzo de los diálogos de paz sostuvo que esto era un efecto de las operaciones decisivas de la Fuerza Pública durante la década precedente. Dado que los diálogos se realizarían sin un cese de las hostilidades, puede ser simple coincidencia que ese año, en febrero, comenzó a aplicarse el plan de guerra ${ }^{36}$ 'Espada de Honor' (Mindefensa, 2012, p. 19; Semana, 2012, Febrero). El plan tuvo como objetivo inicial desarticular a los grupos armados y sus áreas base; es decir, no se centraría solo sobre los cabecillas sino más sobre las estructuras y sus redes de apoyo. Ya el mismo 2012 se divulgó como logro preliminar que solo el $41 \%$ de tales estructuras pudieron realizar alguna acción armada (Mindefensa, 2013, p. 14). Así para cumplir ese objetivo, el plan contempló una ofensiva simultánea con Fuerzas de Tarea Conjunta para cada una de las áreas predefinidas ${ }^{37} \mathrm{y}$ apoyadas por unidades de policía judicial.

También al anunciarse el plan de guerra en 2012 se sugiere cuan decisivas fueron las operaciones mencionadas. El contexto estratégico sobre el cual se articula aquel admitía: "No hay amenaza nacional sino amenazas locales diferenciadas." Para luego explicar: "Por cuenta de ello, la Fuerza Pública combate en la actualidad diferentes amenazas localizadas: el terrorismo de las FARC y del ELN y el crimen organizado..." (Mindefensa, 2013, p. 11). Es decir, los grupos ilegales reducidos en sus efectivos y en su iniciativa, se retiraron hacia pequeñas zonas de refugio. Aquel contexto se reiteró en balance del año siguiente, aunque el Plan Espada de Honor si sufrió reajustes enfatizando que debía persistir en la neutralización de estructuras y en la preservación de los avances de seguridad. En consonancia parece haberse restringido el "espectro de definición del enemigo, dándole una mayor relevancia al ELN y a las bandas criminales." (Mindefensa, 2014, p. 12)

36 Plan de Guerra: "Es el principal documento dentro de los documentos secundarios de la defensa nacional. Su elaboración corresponde al Estado Mayor Conjunto, con base en la decisión del Comandante General de las Fuerzas Militares, derivada de la apreciación estratégica militar general." (FAC, 2013, p. 29).

37 De las Fuerzas de Tarea -F.T. - se reforzaron la F.T. Omega, la F.T. del Sur del Tolima (Zeus) y la F.T. de Nudo de Paramillo (Aquiles). Se crearon cuatro más, a cargo del Ejército Nacional, la Apolo para el área del norte del Cauca, Pegaso para Nariño, Quirón para Arauca y Vulcano para Catatumbo. Una más, a cargo de la Armada Nacional, Poseidón para el Litoral Pacífico y, otra, a cargo de la Fuerza Aérea, Ares para Vichada; en total 9 F.T. 
Si bien lo anterior confirma que las operaciones de bombardeo cumplidas por la Fuerza Aérea Colombiana fueron decisivas para acercar el cese del conflicto armado en Colombia. La capacidad decisoria de la Fuerza Aérea se manifiesta en otros cientos de operaciones diferentes realizadas simultáneamente y que son parte de sus funciones militares. A saber, una de esas funciones es aplicar la fuerza y para cumplirla realiza operaciones de ataque estratégico entre las que se incluye, a su vez, el bombardeo de precisión. No interesa aquí explicar los tipos de operaciones de la doctrina aérea, además que su registro estadístico se somete a los énfasis de cada política de gobierno, pero la tabla 5 resume cuáles y cuantas fueron también decisivas.

Para el caso, desde 2003 la Política de Seguridad Democrática enfatizó en la defensa de poblaciones para contrarrestar la arremetida de los grupos armados ilegales. Al efecto la Fuerza Aérea garantizó la superioridad aérea, realizó misiones de ataque aéreo, de inteligencia aérea, de comando y control, entre otras. La tendencia decreciente de las cifras, de 33 a solo 2 o 0 operaciones, evidenciaría que la Fuerza Aérea contribuyó no solo a repeler en cada suceso a tales grupos sino a disuadir progresivamente otros ataques a poblaciones (FAC, 2008, Informe, p. 5; FAC, 2008, Memoria, p. 1).

Dicha tendencia decreciente permitió a la Fuerza Aérea ajustar los medios para intensificar los ataques estratégicos, ${ }^{38}$ entre los años 2006 y 2007, como se ve en la tabla 5. Más arriba se advirtió que, desde 2007, ello se hizo usando el bombardeo de precisión contra los cabecillas. Pero regularmente fue dirigido a destruir campamentos e infraestructura de los grupos ilegales. Luego, en 2012, la Fuerza Aérea debió intensificar tales ataques, también en respuesta al incremento de acciones terroristas mencionada más arriba; entonces se realizaron 934 operaciones de aplicación de la fuerza, es decir, de ataque, interdicción y apoyo aéreo; las dos primeras incluidas en el Plan Campaña Aérea, sumaron 553 acciones ofensivas (FAC, 2012, p. 1).

En consonancia destaca, a lo largo del período analizado, una tendencia homogénea de la Fuerza Aérea en la realización de operaciones de apoyo aéreo cercano, propias de la misión típica de contra-poder terrestre. Como tal el apoyo aéreo ofrece protección y ventaja táctica a las propias tropas de tierra que se encuentran en combate (FAC, 2013, Manual, p. 90); lo que significa que la Fuerza Aérea ha sido imprescindible en las operaciones del Ejército, la Infantería de Marina y la Policía. Entre 2011 y 2012, de nuevo, debió intensificar tal apoyo bien en la campaña contra el narcotráfico o dentro del Plan Espada de Honor.

La capacidad decisoria de la Fuerza Aérea es menos fortuita si se considera que en 2011 superó varios de sus indicadores de la década previa: el número de

38 Dice ajuste de los medios porque fue después, en 2008, que la Fuerza Aérea recibió 15 aviones A-29, 8 aviones T-37, 4 helicópteros Huey II y 2 UH-60, y 3 aviones transporte C-295. 
horas voladas (87.692 en octubre); el alistamiento de aeronaves ( $73,5 \%$, siendo el promedio mundial de $70 \%$ ) y, todo lo anterior, con el tamaño de flota más grande (319 aeronaves) alcanzado por el país (FAC, 2011, p. 9-11).

Tabla 5. Tipo y número de operaciones Fuerza Aérea ${ }^{39}$.

\begin{tabular}{|l|l|l|l|l|l|l|l|l|l|l|l|l|}
\hline & $\mathbf{2 0 0 3}$ & $\mathbf{2 0 0 4}$ & $\mathbf{2 0 0 5}$ & $\mathbf{2 0 0 6}$ & $\mathbf{2 0 0 7}$ & $\mathbf{2 0 0 8}$ & $\mathbf{2 0 0 9}$ & $\mathbf{2 0 1 0}$ & $\mathbf{2 0 1 1}$ & $\mathbf{2 0 1 2}$ & $\mathbf{2 0 1 3}$ & $\mathbf{2 0 1 4}$ \\
\hline Defensa de poblaciones & 33 & 21 & 19 & 7 & 2 & 2 & $(0)$ & $(2)$ & & & & \\
\hline $\begin{array}{l}\text { Ataque a campamentos / } \\
\text { y estratégicos }\end{array}$ & 109 & 242 & 304 & 757 & 690 & 443 & $(136)$ & $(47)$ & $(11)$ & $(10)$ & n.d. & $(0)$ \\
\hline Apoyo aéreo cercano & 316 & 334 & 323 & 328 & 305 & 292 & $(119)$ & 200 & 366 & 381 & n.d. & 133 \\
\hline Interdicción & n.d. & n.d. & n.d. & n.d. & n.d. & n.d. & n.d. & 268 & 369 & 543 & n.d. & 244 \\
\hline & & & & & & & & & & & & \\
\hline Trazas sospechosas & 639 & 462 & 329 & 159 & 76 & 43 & 16 & 12 & 20 & 17 & 15 & 06 \\
\hline Aeronaves inmovilizadas & & n.d. & 12 & 9 & 13 & 45 & 92 & 101 & 52 & 84 & 113 & 166 \\
\hline Aeronaves inutilizadas & & n.d. & 7 & 7 & 7 & 9 & 15 & 15 & 32 & 28 & 43 & 25 \\
\hline Lanchas inmovilizadas & & & & & 5 & 22 & 9 & n.d. & n.d. & 3 & 10 & 20 \\
\hline
\end{tabular}

Fuente: FAC. Informes de gestión, 2006 a 2014; Mindefensa (2010, p. 217, 230); Neira (2014). [Entre paréntesis, cifra parcial; n.d.: datos no disponibles].

Por último, otro ámbito en el cual la Fuerza Aérea fue decisiva para acercar el cese del conflicto armado en Colombia, ha sido la lucha contra el narcotráfico. Aunque ya en 1984 el embajador de EE.UU. en Colombia, Lewis Tambs, denunció el nexo entre los grupos armados ilegales y el narcotráfico (El Espectador, 2010, párr. 4), apenas en noviembre de 2002 el gobierno Bush $^{40}$ autorizó que la asistencia estadounidense contra el narcotráfico en Colombia se usara también contra la insurgencia (MoYAR et al., 2014, p. 28).

Con la reactivación, al año siguiente, del programa de interdicción la Fuerza Aérea Colombiana reforzó la defensa nacional. Al efecto, ese mismo 2003, EE.UU. prestó a Colombia 3 aeronaves Cessna Citation 560, plataformas para localizar

39 Las operaciones con Aplicación de la Fuerza incluyen: Ataques estratégicos (contra el centro de gravedad del enemigo, sean cabecillas, infraestructura y medios de comunicación); Interdicción (ataques a movimientos y abastecimientos del enemigo con el fin de neutralizar, demorar o destruir su capacidad delictiva); Apoyo aéreo cercano (provee apoyo directo a las fuerzas de superficie para asegurar la supervivencia de las fuerzas amigas), concentrando el esfuerzo principal en las áreas del Salto Estratégico, buscando a través de este tipo de operaciones doblegar la voluntad de lucha del enemigo"... (FAC, 2010, Memoria, p. 1).

40 Evaluando el Plan Colombia Rabasa y Chalk objetaban que atacar el narcotráfico debilitaría a los grupos ilegales, apoyando la idea de una intervención del resto de Suramérica contra Colombia (2001, p. 93-94). Tal intervención fue tema en 1998 y 1999: desde el Senado de EU hasta la OEA(El Tiempo, 1998-12-7, p. 9A; Tiempo, 1999-06-9, p. 1A), con variada oposición de Brasil, Chile, Cuba y Perú (Esquivel, 2001. p. 73-75). 
las trazas $^{41}$ de aviones ilegales y dedicados al narcotráfico. Las zonas de este control aéreo incluyeron las fronteras con Brasil, Panamá, Perú y Venezuela, y el mar Caribe (El Tiempo, 2003, Agosto; El Espectador, 2003, Mayo). La Fuerza Aérea logró reducir los vuelos ilegales que usaban el espacio aéreo colombiano, de 639 trazas sospechosas detectadas en 2003 se redujo a 6 en 2014 (NeIRA, 2014, párr. 12).

Del mismo modo, al tiempo que reducía los vuelos ilegales la Fuerza Aérea incrementó su efectividad contra los medios usados por el narcotráfico. Pasó de inmovilizar 12 aeronaves (2005) a 113 (2013), como pasó de inutilizar 7 (2005) a 43 (2013) aeronaves. Desde el 2007 el programa de interdicción se hizo extensivo a medios marítimos, incrementando la seguridad marítima de Colombia en asocio con la Armada Nacional. La interdicción aérea y marítima contra el narcotráfico redujo los flujos financieros y de contrabando de los grupos ilegales en Colombia, aunque estos se financian también con la minería ilegal.

El papel decisivo de la Fuerza Aérea en el control del espacio aéreo de Colombia, hizo que los flujos del narcotráfico se desplazaran hacia otros países de la región. Por ello, la Fuerza Aérea asumió el establecimiento de convenios y de procedimientos de interdicción con países como: Estados Unidos, Brasil, Perú, Ecuador, Chile y Paraguay. También reforzando la interdicción en el Mar Caribe, "se han podido establecer contactos directos con Honduras, Venezuela, México, Nicaragua, Guatemala, Panamá, Belice, Haití y República Dominicana, donde se han presentado excelentes resultados operacionales en la lucha mundial contra el narcotráfico." (FAC, 2012, p. 6)

Por lo anterior, y según dispuso el Plan Espada de Honor, en 2012 la Fuerza Aérea recibió a su cargo la Fuerza de Tarea de Acción Conjunta, Combinada e Interagencial 'ARES'. Con sede en Marandúa (Vichada), ${ }^{42}$ en la base del Grupo Aéreo del Oriente -GAORI-, esta Fuerza tiene como propósito combatir el narcotráfico y a los grupos armados ilegales en los departamentos de Arauca, Vichada y Guainía (FAC, 2015, Marzo; FAC, 2013, Marzo). En 2015, la Fuerza de Tarea ARES realizó una de las operaciones contundentes contra la minería ilegal, afectando en $\$ 20.050$ millones por mes los ingresos del grupo ilegal (La Reportería, 2015, Mayo).

\footnotetext{
$41 \quad$ Trazas aéreas, se refiere a la trayectoria descrita por un punto luminoso sobre la pantalla de radar; cfr. acepción RAE (2001). Diccionario de la Lengua Española (22. ed.). Madrid: Espasa.

42 Marandúa, puesto adelantado del Comando Aéreo $\mathrm{N}^{\circ}$. 2, fue primero en 1994 estación de un radar TPS-43 operado por la Fuerza Aérea de EU; desde 1996 se hizo sede del GAORI (FAC, 2004, Agosto) y desde 2012 sede también de la Fuerza de Tarea 'Ares' (FAC, 2015, Marzo).
} 


\section{REFERENCIAS}

\section{Fuentes primarias}

Acuerdo general para la terminación del conflicto y la construcción de una paz estable y duradera (2012, Agosto 26). Recuperado de: https://www.mesadeconversaciones.com.co/sites/default/files/acuerdogeneralterminacionconflicto.pdf

Corte Constitucional (2001, Enero 24). Sentencia C-048 /01. Recuperado de: http://www.corteconstitucional.gov.co/sentencias/2001/C-048-01.rtf

Fuerza Aérea Colombiana -FAC (2014). Informe de gestión 2014. Bogotá: La Fuerza. Recuperado de: https://www.fac.mil.co/informe-2014-0

Fuerza Aérea Colombiana -FAC (2013). Informe de gestión 2013. Bogotá: La Fuerza. Recuperado de: https://www.fac.mil.co/informe-2013

Fuerza Aérea Colombiana -FAC (2013). Manual de doctrina básica aérea y espacial (MADBA; 4a. ed.). Bogotá: La Fuerza. (Manual FAC 0-E, Público). Recuperado de: https://www.doctrinafac.mil.co/manual-de-doctrina$\mathrm{b} \% \mathrm{C} 3 \% \mathrm{~A} 1$ sica-a $\% \mathrm{C} 3 \%$ A9rea-y-espacial-mabda

Fuerza Aérea Colombiana -FAC (2012). Informe de gestión 2012. Bogotá: La

Fuerza. Recuperado de: https://www.fac.mil.co/informe-2012

Fuerza Aérea Colombiana -FAC (2011). Informe de gestión 2011. Bogotá: La

Fuerza. Recuperado de: https://www.fac.mil.co/informe-2011

Fuerza Aérea Colombiana -FAC (2010). Informe de gestión 2010. Bogotá: La

Fuerza. Recuperado de: https://www.fac.mil.co/informe-2010

Fuerza Aérea Colombiana -FAC (2010). Memorias al Congreso 2009-2010.

Bogotá: La Fuerza. Recuperado de: https://www.fac.mil.co/memorias-alcongreso-2009-2010

Fuerza Aérea Colombiana -FAC (2009). Informe de gestión 2009. Bogotá: La

Fuerza. Recuperado de: https://www.fac.mil.co/informe-2009

Fuerza Aérea Colombiana -FAC (2008). Informe de gestión 2008. Bogotá: La

Fuerza. Recuperado de: https://www.fac.mil.co/informe-2008

Fuerza Aérea Colombiana -FAC (2007). Informe de gestión 2007. Bogotá: La Fuerza. Recuperado de: https://www.fac.mil.co/informe-2007

Fuerza Aérea Colombiana -FAC (2006). Informe de gestión 2006. Bogotá: La Fuerza. Recuperado de: https://www.fac.mil.co/informe-2006

Fuerza Aérea Colombiana (2004, Agosto). Grupo Aéreo del Oriente-GAORI. Marandúa (Vichada): La Fuerza. 
Ministerio de Defensa Nacional -Mindefensa (2015, Junio 22). Acta de informe de gestión. Bogotá: El Ministerio. Recuperado de: https://www.mindefensa.gov. co/irj/go/km/docs/Mindefensa/Documentos/descargas/Prensa/Documentos/ informe_empalme_mindefensa_pinzon.pdf

Ministerio de Defensa Nacional (2015). Memorias al Congreso 2014-2015. Bogotá: Imprenta Nacional. Recuperado de: https://www.mindefensa.gov. co/irj/go/km/docs/Mindefensa/Documentos/descargas/Prensa/Documentos/ memorias2014-2015.pdf

Ministerio de Defensa Nacional (2014). Memorias al Congreso 2013-2014. Bogotá: Imprenta Nacional. Recuperado de: https://www.mindefensa.gov. co/irj/go/km/docs/mindefensa/documentos/descargas/prensa/documentos/ memorias2013-2014.pdf

Ministerio de Defensa Nacional (2013). Memorias al Congreso 2012-2013. Bogotá: Imprenta Nacional. Recuperado de: https://www.mindefensa.gov. $\mathrm{co} / \mathrm{irj} / \mathrm{go} / \mathrm{km} /$ docs$/$ mindefensa/documentos/descargas/prensa/documentos/ memorias2012-2013.pdf

Ministerio de Defensa Nacional (2012). Memorias al Congreso 2011-2012. Bogotá: Imprenta Nacional. Recuperado de: https://www.mindefensa.gov. co/irj/go/km/docs/mindefensa/documentos/descargas/prensa/documentos/ memorias2011-2012.pdf

Ministerio de Defensa Nacional (2011). Informe del Ministro al Congreso [2010-2011]. Bogotá: Imprenta Nacional. Recuperado de: https://www. mindefensa.gov.co/irj/go/km/docs/Mindefensa/Documentos/descargas/ Prensa/Documentos/memorias2010-2011.pdf

Ministerio de Defensa Nacional (2010). Memorias al Congreso 2009-2010. Bogotá: Imprenta Nacional. Recuperado de: https://www.mindefensa. gov.co/irj/go/km/docs/Mindefensa/Documentos/descargas/normatividad/ estrategiaplaneacion/sistemadecontrolinterno/gpa/informesdegestion/ memorias2009-2010.pdf

Ministerio de Defensa Nacional (2007). Política de Consolidación de la Seguridad Democrática. Bogotá: El Ministerio. Recuperado de: https://www.oas.org/ dsp/documentos/politicas_publicas/colombia\%202.pdf

Ministerio de Defensa Nacional (2007, Febrero). Rendición de cuentas 20022006. Bogotá: El Ministerio. Recuperado de: https://www.mindefensa.gov. co/irj/go/km/docs/mindefensa/documentos/descargas/sobre_el_ministerio/ rendicioncuentas/audiencia_publica_2002_2006.pdf

Ministerio de Defensa Nacional (2003). Política de Defensa y Seguridad Democrática. Bogotá: El Ministerio. Recuperado de: https://www.oas.org/ $\mathrm{csh} / \mathrm{spanish} /$ documentos/Colombia.pdf 
Presidencia de la República (1998). Resolución No 85 del 14 de octubre de 1998 “Por la cual se declara la iniciación de un proceso de paz, se reconoce el carácter político de una organización armada y se señala una zona de distensión". Recuperado de: http://pdba.georgetown.edu/clas\%20research/library $\% 20$ and $\% 20$ documents/peace\%20processes/1998-2002/1998\%20oct_resolucion\%2085.doc

Vicepresidencia de la República (2003). Los derechos humanos en el departamento del Vaupés. Bogotá: La Vicepresidencia. Recuperado de: http://reliefweb. int/sites/reliefweb.int/files/resources/a42d0dfe62e5b79fc1256e2900494151govcol-col-28jan10.pdf

Fuentes secundarias / Artículos indexados y libros

BARros, C. (2006). «L'historiographie et l'histoire immédiates: l'expérience latine de l'Histoire en débat (1993-2006)». Recuperado de: http://www.h-debate. $\mathrm{com} /$ Spanish/presentaciones/lugares/Toulouse/Toulouse_es1.htm

Bushnell, D. (1994). Colombia una nación a pesar de sí misma: De los tiempos precolombinos a nuestros días. Bogotá: Planeta.

Centro Nacional de Memoria Histórica-CNMH (2013). Guerrilla y población civil: trayectoria de las Farc 1949-2013. Bogotá: Imprenta Nacional.

Comisión Histórica del Conflicto y sus Víctimas (2015, Febrero). Contribución al entendimiento del conflicto armado en Colombia. Recuperado de: https://www.mesadeconversaciones.com.co/sites/default/files/informe $\% 20$ comisi_n $\% 20$ hist_rica $\% 20$ del $\% 20$ conflicto $\% 20 \mathrm{y} \% 20$ sus $\% 20$ v_ctimas. $\% 20$ la $\% 20$ habana $\% 2 \mathrm{c} \% 20$ febrero\%20de $\% 202015$.pdf

EsPINO, A. (2001) La renovación de la historia de las batallas. Revista de historia militar, 91, pp. 159-174. Recuperado de: http://publicaciones.defensa.gob.es/ docs/default-source/revistaspdf/rhm_091.pdf?sfvrsn=0\&download=true

Esquivel, R. (2003). Un laberinto impuesto. En: Rabasa, Á. El laberinto colombiano: propuestas para la resolución del conflicto. (pp. 47-58) Bogotá: Universidad Externado.

EsQuivel, R. (2002, Abril). Colonización y violencia en los Llanos, 1949-1953. Memoria y Sociedad, 6 (11), pp. 57-84. Recuperado de: http://revistas. javeriana.edu.co/index.php/memoysociedad/article/view/7748

EsQuivel, R. (2001). Colombia indefensa. Bogotá: Planeta.

Fuerza Aérea Colombiana -FAC (2005). Vocación de victoria Fuerza Aérea Colombiana 1990-2005. Bogotá: FAC. 
Fundación Ideas para la paz -FIP (2006, Febrero 3). La guerra de La Macarena. Siguiendo el conflicto, 40. Recuperado de: http://archive.ideaspaz.org/images/ boletin_conflicto40.pdf

Gamba, R., Prado, J., Prieto, C. \& Tarazona, A. (2012). La Operación Odiseo: un análisis desde la prospectiva militar (Trabajo de grado CEM). Bogotá: Escuela Superior de Guerra.

GÉlvez, L., Correa, A., Gutiérrez, J., Henao, A. \& Rojas, D. (2014). Historiografía contemporánea de la Fuerza Aérea Colombiana: operaciones Sol naciente, Fénix, Alcatraz, Odiseo y Sodoma (Trabajo de grado CEM). Bogotá: Escuela Superior de Guerra.

GonZÁlez, H. (1990). Antecedente geográfico de La Macarena (p. 115-143). En: Universidad Nacional. La Macarena: Reserva biológica de la humanidad; territorio de conflictos. Bogotá: Editorial UN. Recuperado de: http://www. bdigital.unal.edu.co/1435/5/03CAPI02.pdf

Gray, C. (2002, April). Defining and Achieving Decisive Victory. Carlisle, PA: Strategic Studies Institute.

Guerrero, J. (1991). Los años del olvido. Bogotá: Tercer Mundo.

Haulman, D. (2014). Precision Aerial Bombardment of Strategic Targets: Its Rise, Fall, and Resurrection (pp. 148-157). Air Power History, 60th Anniversary.

Keegan, J. (1995). Historia de la guerra. Barcelona: Planeta.

KeEgan, J. (1990). El rostro de la batalla. Madrid: Ediciones Ejército.

MaO, Tse-tung (1968). Sobre la guerra prolongada. Obras Escogidas. Pekín: Ediciones en Lenguas Extranjeras. T. 2. Recuperado de: https://www. marxists.org/espanol/mao/escritos/pw38s.html

Martínez, G. (2006). Hablan los generales: las grandes batallas del conflicto colombiano... Bogotá: Norma.

Misión de Observación Electoral -MOE (2010). Monografía político electoral Departamento de Vaupés 1997 a 2007. Bogotá: MOE.

Moyar, M., Pagan, H. \& Griego, W. (2014, July). Persistent Engagement in Colombia (Report 14-3). MacDill AFB (Fl.): JSO University. Recuperado de: http://jsou. socom.mil/pubspages/jsou14-3_moyar-pagan-griego_colombia_final.pdf

PARdo, R. (2004). La historia de las guerras. Bogotá: Ediciones B.

Pecaut, D. (2001). Guerra contra la sociedad. Bogotá: Espasa.

PeÑA, J. (2011). Mitú: ciudad amazónica, territorialidad indígena. Leticia: Universidad Nacional de Colombia. Recuperado de: http://www.bdigital. unal.edu.co/9726/ 
Perea, L. \& Murcia, J. (2014). Historiografía contemporánea de la Fuerza Aérea Colombiana: operaciones 'Vuelo del ángel' y 'Retoma zona de distensión' (Trabajo de grado CEM). Bogotá: Escuela Superior de Guerra.

Rabasa, A., y Chalk, P. (2001). Colombian Labyrinth: The Synergy of Drugs and Insurgency and Its Implications for Regional Stability. Santa Mónica: RAND. Recuperado de: Rabasa, http://www.rand.org/pubs/monograph_ reports/MR1339.html

SÁNCHEZ, G. (coord.) (2009). Colombia: violencia y democracia. Medellín: IEPRI.

SÁnchez, G. y Peñaranda, R. (Eds.) (1997). Pasado y presente de la violencia en Colombia. Bogotá: Cerec.

Santos, J. (2007). Historia militar del Ejército de Colombia. Bogotá: Centro de Estudios Históricos del Ejército.

Santos, J. (2002). El Ejército en la guerra irregular de Colombia: una visión histórico-estratégica del conflicto colombiano (1948-2002). Bogotá: Imprenta FF.MM.

Santos, M. (2014). El poder de la Fuerza Aérea Colombiana: La operación Vuelo de Ángel y el cambio en la asimetría de poder entre las FF.MM y las Farc-ep (Trabajo de grado Ciencia Política). Bogotá: Universidad del Rosario.

Sauvage, P. (1998, Diciembre) Una historia del tiempo presente. Historia Crítica, n. 17 , p. $59-70$.

SPencer, D. y Gómez, J. et al. (2011, Junio). Colombia: Camino a la recuperación: seguridad y gobernabilidad 1982 -2010. Washington: CHDS. Recuperado de: http://digitalndulibrary.ndu.edu/cdm/ref/collection/chdspubs/id/18089

Valencia, Á. (1992). Testimonio de una época. Bogotá: Planeta.

Villalobos, J. (1993). Fuerza Aérea Colombiana (v. 5). En: Valencia, A. Historia de las Fuerzas Militares de Colombia. Bogotá: Planeta.

Prensa y páginas web:

ACNUR (2007). Diagnóstico departamental Vaupés. Recuperado de: http://www. acnur.org/t3/uploads/media/COI_2190.pdf?view $=1$

Alcaldía de El Carmen de Bolívar (2013, Noviembre 1). Nuestro municipio. Recuperado de: http://www.elcarmen-bolivar.gov.co/informacion_general.shtml

Alcaldía de Mitú (2015, Febrero 20). Nuestro municipio. Recuperado de: http:// www.mitu-vaupes.gov.co/index.shtml

Alcaldía de Suárez (2012, Agosto 28). Nuestro municipio. Recuperado de: http:// suarez-cauca.gov.co/informacion_general.shtml 
Armada Nacional de Colombia-ARC (2007...) Continúa operación 'Alcatraz'. Recuperado de: https://www.armada.mil.co/eng/node/5104

Bedoya, J. (2012, Octubre 23). Así cayó ‘Alfonso Cano'. El Tiempo. Recuperado de: http://www.eltiempo.com/archivo/documento/cms-12330024

Bedoya, J. (2010, Septiembre 23). Así se planeó y ejecutó la Operación 'Sodoma'. El Tiempo. Recuperado de: http://www.eltiempo.com/archivo/documento/ cms-7960880

Bedoya, J. (2007, Diciembre 18). Se acabó la suerte del 'Negro Acacio'. Recuperado de: http://www.eltiempo.com/archivo/documento/mam-2770504

Bolaños, E. (2011, Noviembre 7). Así se vivió 'Odiseo'. El Espectador. Recuperado de: http://www.elespectador.com/noticias/judicial/asi-se-vivioodiseo-articulo-310039

Castrillón, G. (2011, Diciembre 17). La 'Operación Odiseo', la muerte de Alfonso Cano. El Espectador. Recuperado de: http://www.elespectador. $\mathrm{com} / \mathrm{muerte}$-de-alfonso-cano/operacion-odiseola-muerte-de-alfonso-canoarticulo-317180

Centro Nacional de Memoria Histórica -CNMH (2014). Proceso de paz con las Autodefensas Unidas de Colombia -AUC. Recuperado de: http:// centromemoria.gov.co/wp-content/uploads/2014/11/Proceso_de_paz_con_ las_Autodefensas.pdf

Colprensa (2013, Junio 7). Condenan a la Nación por segunda vez por despeje de 'El Caguán'. Frontera Informativa. Recuperado de: https://fronterainformativa. wordpress.com/author/fronterainformativa/

EFE (2002, Febrero 21). Continúan bombardeos contra las Farc: tres civiles muertos. Cooperativa. Recuperado de: http://www.cooperativa.cl/p4 noticias/site/artic/20020221/pags/20020221165200.html

El Diario (2010, Septiembre 24). Así se construyó la Operación Sodoma. Recuperado de: http://www.eldiario.com.co/seccion/judicial/as-se-construyla-operaci-n-sodoma100923.html

El Espectador (2010, Diciembre 11). La diplomacia con Washington. Recuperado de:-http://www.elespectador.com/impreso/articuloimpreso-239868diplomacia-washington

El Espectador (2003, Mayo 4). El ABC de la interdicción (p. 14A; versión impresa).

El Espectador (2001, Diciembre 16). Una inteligencia a prueba (p. 7A; versión impresa).

El País (2013, Julio 16). Condenan a la presidencia por robo de ganado en zona de despeje. El País On line. Recuperado de: http://www.elpais.com.co/elpais/ temas/andres-pastrana/ 
El País (2007, Septiembre 4). "Tropas del Ejército dieron de baja al 'Negro Acacio'. Recuperado de: http://historico.elpais.com.co/paisonline/notas/ Septiembre042007/nac00.html

El País (2003, Febrero 20). Un año de la retoma del Caguán. El País On line. Recuperado de: http://historico.elpais.com.co/paisonline/calionline

El Tiempo (2011, Noviembre 6). Cuatro claves del Estado que pusieron a las Farc en su peor momento. Recuperado de: http://www.eltiempo.com/archivo/ documento/CMS-10713652

El Tiempo (2011, Noviembre 5). [Mapa: Zona de ofensiva contra Alfonso Cano]. Recuperado de: https://esperanzaav.wordpress.com/page/21/

El Tiempo (2007, Septiembre 5). La muerte de 'El sietevidas'. Recuperado de: http://www.eltiempo.com/archivo/documento/cms-3710030

El Tiempo (2003, Agosto 22). Cacería a mil vuelos del narcotráfico. Recuperado de: http://www.eltiempo.com/archivo/documento/MAM-1002293

El Tiempo (2001, Agosto 19). Últimas operaciones exitosas (p. 1-17; versión impresa).

El Tiempo (2000, Julio 17). Farc amplían zona de distensión. Recuperado de: http://www.eltiempo.com/archivo/documento/mam-1280032

El Tiempo (1999, Agosto 16). La guerrilla deja sin policía a municipios. Recuperado de: http://www.eltiempo.com/archivo/documento/mam-896475

El Tiempo (1999, Junio 9). Fuerza de intervención pide EU a la OEA (p. 1A; versión impresa).

El Tiempo (1998, Diciembre 7). Viraje de EU frente a Colombia (p. 9A; versión impresa).

El Tiempo (1998, Noviembre 4). Batalla nocturna para recuperar Mitú. Recuperado de: http://www.eltiempo.com/archivo/documento/mam-846204

Escuela de Inteligencia Aérea-ESINA (2014, Julio 10). Historia de la JIN. Recuperado de: https://www.esina.mil.co/historia-1

Fuerza Aérea Colombiana -FAC (2003, Mayo 23). Tras el Negro Acacio. Recuperado de: http://www.academiahistoriaaerea.mil.co/tras-el-negro-acacio

Fuerza Aérea Colombiana (2015, Marzo 27). Fuerza de Tarea Conjunta ARES conmemora tres años al servicio del país. Recuperado de: https://www.fac. mil.co/fuerza-de-tarea-conjunta-ares-conmemora-tres-a $\% \mathrm{C} 3 \% \mathrm{~B} 1$ os-alservicio-del-pa $\% \mathrm{C} 3 \% \mathrm{ADs}$

Fuerza Aérea Colombiana (2013, Marzo 28). Fuerza de Tarea de Acción Conjunta... Recuperado de: https://www.fac.mil.co/fuerza-de-tarea-de-acci\%C3\%B3n- 
conjunta- $\%$ E2\%80\%9Cun-s\%C3\%B3lo-esfuerzo-decisi $\% \mathrm{C} 3 \% \mathrm{~B} 3 \mathrm{n}-\mathrm{y}-$ contundencia $\%$ E2\%80\%9D-\%E2\%80\%9Cares $\%$ E2\%80\%9D

Giraldo, J. (2014, Octubre 20). El fuerte bombardeo que precedió el abatimiento de 'Cano'. Noticias RCN. Recuperado de: http://www.noticiasrcn.com/ nacional-pais/el-fuerte-bombardeo-precedio-el-abatimiento-cano

GonzÁlez, C. (2013). Los nombres de la guerra en la memoria histórica. Recuperado de: http://centromemoria.gov.co/wp-content/uploads/2013/11/ Los-nombres-de-esta-guerra.pdf

Infobae (2011, Noviembre 5). Así fue la "Operación Odiseo" que acabó con la vida de Alfonso Cano. Recuperado de: http://www.infobae. com/2011/11/05/1037324-asi-fue-la-operacion-odiseo-que-acabo-la-vidaalfonso-cano

La Reportería (2015, Mayo 16). Anostumus, la más dura operación contra la minería ilegal en la última década. Recuperado de: http://www.lareporteria. com/contenidos/Info_Segundo_Nivel.php?Id_CN2=639\&Id_CN1=20\#. Vn79i7aGuko

Las Fuerzas (2011, Noviembre). Contundencia contra terroristas de las Farc. Las Fuerzas, 11. Recuperado de: http://www.cgfm.mil.co/documents/10184/177460/ las-fuerzas-11.pdf/ff4f0fa4-166e-4a18-8ccd-9d9ac6217eae

LeAl, F. (2010, Enero 18). La política de seguridad democrática. Razón Pública. Recuperado de: http://www.razonpublica.com/index.php/conflicto-drogasy-paz-temas-30/693-la-polca-de-seguridad-democrca.html

Mendoza, M. (2006, Marzo 26). Llamar las cosas por su nombre. El Tiempo. (p. 1-29; versión impresa).

Ministerio de Defensa Nacional-Mindefensa (2007). Campaña militar 'Alcatraz'. Recuperado de: http://www.mindefensa.gov.co/descargas/Documentos Home2/martin_caballero.pps

NeIRA, J. (2014, Noviembre 19). Lecciones aprendidas en la lucha contra el narcotráfico. En Comisión Interamericana para el control del abuso de drogas -CICAD- 56 . Período de Sesiones, Guatemala. Recuperado de: http://www. cicad.oas.org/apps/Document.aspx?Id=3029

Noguera, I. (2011, Noviembre 6). El Chirriadero, donde murió 'Cano', punto inhóspito en las montañas. El Tiempo. Recuperado de: http://www.eltiempo. com/archivo/documento/CMS-10713662

Padilla, N. (1998, Noviembre 5) Colombia: el ejército recuperó el pueblo copado por las Farc. Clarín. Recuperado de: http://edant.clarin.com/diario/1998/11/05/ i-04201d.htm 
Priest, D. (2013, December 21). Covert action in Colombia. The Washington Post. Recuperado de: http://www.washingtonpost.com/sf/investigative/2013/12/21/ covert-action-in-colombia/

Radio Santafé (2015, Mayo 27). Condenan a 20 años de cárcel a 2 guerrilleros de las Farc por toma de Mitú en donde fueron masacradas 43 personas. Recuperado de: http://www.radiosantafe.com/2015/05/27/condenan-a-20anos-de-carcel-a-2-guerrilleros-de-las-farc-por-toma-de-mitu-en-dondefueron-masacradas-43-personas/

Reportero 24 (2011, Noviembre 5). Colombia: El operativo que acabó con (a) Alfonso Cano. Recuperado de: http://www.reportero24.com/2011/11/ colombia-el-operativo-que-acabo-con-a-alfonso-cano/

Restrepo, O. (1999, Marzo 22) Mitú: el inicio de la contraofensiva. El Tiempo. Recuperado de: http://www.latinamericanstudies.org/colombia/mitu3.htm

Rubiano-Groot, R. (2002, Julio) El vuelo del Pegaso en la zona Delta. Revista Aeronáutica, 231.

Rueda, R. (2011, Diciembre). Sodoma reafirma la superioridad de la Fuerza Aérea en las operaciones militares. Revista Aeronáutica, 263.

Semana (2012, Febrero 2). La nueva estrategia contra las Farc. Recuperado de: - http://www.semana.com/nacion/articulo/la-nueva-estrategia-contrafarc/253985-3

Semana (2010a, Septiembre 25). Pilotos cuentan detalles de la operación 'Sodoma'. Recuperado de: http://www.semana.com/nacion/articulo/pilotoscuentan-detalles-operacion-sodoma/122486-3

Semana (2010b, Septiembre 23). Así fue la operación 'Sodoma' que dio muerte a 'Jojoy'. Recuperado de: http://www.semana.com/nacion/articulo/asioperacion-sodoma-dio-muerte-jojoy/122357-3

Semana (2009, Diciembre 6). Golpes silenciosos. Recuperado de: http://www. semana.com/nacion/articulo/golpes-silenciosos/111440-3

Semana (2007, Septiembre 3). Mindefensa dice que las autoridades destruyeron 'el bunker' de las Farc, en el corazón de la selva. Recuperado de: http://www. semana.com/on-line/articulo/mindefensa-dice-autoridades-destruyeron-elbunker-farc-corazon-selva/88048-3

Semana (2001, Abril 9). Golpe maestro. Recuperado de: http://www.semana. com/nacion/articulo/golpe-maestro/45585-3

Semana (1998, Diciembre 12). El síndrome de Jacobo. Recuperado de: http:// www.semana.com/nacion/articulo/el-sindrome-de-jacobo/37900-3 
Semana (1998, Octubre 10). Cuál despeje. Recuperado de: http://www.semana. com/nacion/articulo/cual-despeje/37484-3

Valencia, A. (1998, diciembre). Cuarto momento militar del siglo XX. Revista de las Fuerzas Armadas, n. 169.

Vanguardia Liberal (2011, Noviembre 6). El paso a paso de la operación 'Odiseo'. Recuperado de: http://www.vanguardia.com/actualidad/ colombia/130287-el-paso-a-paso-de-la-operacion-odiseo

Vanguardia Liberal (2015, Agosto 4). Conozca el top 5 de los bombardeos a las Farc. Recuperado de: http://www.vanguardia.com/colombia/322212conozca-el-top-5-de-los-bombardeos-a-las-farc

VÁsquez, C. (2001, Marzo 1). Golpe al Tranquilandia de las Farc. El Tiempo. Recuperado de: http://www.eltiempo.com/archivo/documento/mam601662

Verdadabierta.com (2015, Marzo 11). Los bombardeos cambiaron la guerra en Colombia. Recuperado de: http://www.verdadabierta.com/procesosde-paz/farc/5659-los-bombardeos-cambiaron-la-guerra-en-colombia 